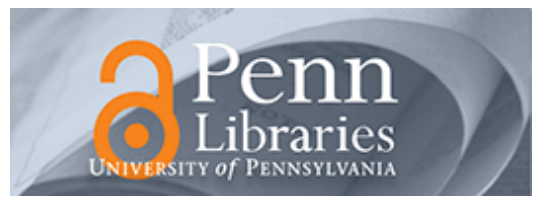

University of Pennsylvania

ScholarlyCommons

Accounting Papers

Wharton Faculty Research

$5-2010$

\title{
Chief Executive Officer Equity Incentives and Accounting Irregularities
}

Christopher S. Armstrong

University of Pennsylvania

Alan D. Jagolinzer

David F. Larcker

Follow this and additional works at: https://repository.upenn.edu/accounting_papers

Part of the Accounting Commons

\section{Recommended Citation}

Armstrong, C. S., Jagolinzer, A. D., \& Larcker, D. F. (2010). Chief Executive Officer Equity Incentives and Accounting Irregularities. Journal of Accounting Research, 48 (2), 225-271. http://dx.doi.org/10.1111/ j.1475-679X.2009.00361.x

This paper is posted at ScholarlyCommons. https://repository.upenn.edu/accounting_papers/63

For more information, please contact repository@pobox.upenn.edu. 


\title{
Chief Executive Officer Equity Incentives and Accounting Irregularities
}

\begin{abstract}
This study examines whether Chief Executive Officer (CEO) equity-based holdings and compensation provide incentives to manipulate accounting reports. While several prior studies have examined this important question, the empirical evidence is mixed and the existence of a link between CEO equity incentives and accounting irregularities remains an open question. Because inferences from prior studies may be confounded by assumptions inherent in research design choices, we use propensity-score matching and assess hidden (omitted variable) bias within a broader sample. In contrast to most prior research, we do not find evidence of a positive association between CEO equity incentives and accounting irregularities after matching CEOs on the observable characteristics of their contracting environments. Instead, we find some evidence that accounting irregularities occur less frequently at firms where CEOs have relatively higher levels of equity incentives.
\end{abstract}

\section{Keywords}

equity incentives, accounting restatements, propensity score matching

Disciplines

Accounting 


\title{
Chief Executive Officer Equity Incentives and Accounting Irregularities
}

\author{
Christopher S. Armstrong \\ carms@wharton.upenn.edu \\ The Wharton School \\ University of Pennsylvania \\ 1300 Steinberg-Dietrich Hall \\ Philadelphia, PA 19104-6365 \\ Alan D. Jagolinzer \\ jagolinzer@stanford.edu \\ Stanford University \\ Graduate School of Business \\ 518 Memorial Way \\ Stanford, CA 94305-5015 \\ David F. Larcker \\ larcker_david@gsb.stanford.edu \\ Stanford University \\ Graduate School of Business \\ 518 Memorial Way \\ Stanford, CA 94305-5015
}

Revised September 7, 2009

We thank Paul Rosenbaum for insightful methodological discussions and Bo Lu for making available his nonbipartite matching algorithm. We also thank Doug Skinner (editor), an anonymous referee, John Core, Ian Gow, Wayne Guay, Christopher Ittner, Daniel Taylor, Andrew Yim, and workshop participants at Penn State University and Tilburg University for helpful feedback. Jagolinzer acknowledges financial support from the James and Doris McNamara Faculty Fellowship and the John A. and Cynthia Fry Gunn Faculty Scholarship. 


\title{
Chief Executive Officer Equity Incentives and Accounting Irregularities
}

\begin{abstract}
This study examines whether Chief Executive Officer (CEO) equity-based holdings and compensation provide incentives to manipulate accounting reports. While several prior studies have examined this important question, the empirical evidence is mixed and the existence of a link between CEO equity incentives and accounting irregularities remains an open question. Because inferences from prior studies may be confounded by assumptions inherent in research design choices, we use propensity-score matching and assess hidden (omitted variable) bias within a broader sample. In contrast to most prior research, we do not find evidence of a positive association between CEO equity incentives and accounting irregularities after matching CEOs on the observable characteristics of their contracting environments. Instead, we find some evidence that accounting irregularities occur less frequently at firms where CEOs have relatively higher levels of equity incentives.
\end{abstract}

Keywords: equity incentives; accounting restatements; propensity score matching

JEL Classification: J33, M41, M52 


\section{Chief Executive Officer Equity Incentives and Accounting Irregularities}

\section{Introduction}

This study examines the relationship between chief executive officer (CEO) equity incentives and accounting irregularities (e.g., restatements, Securities and Exchange Commission Accounting and Auditing Enforcement Releases, and shareholder class action lawsuits). Although equity holdings may alleviate certain agency problems between executives and shareholders, concerns have arisen among researchers, regulators, and the business press that "high-powered" equity incentives might also motivate executives to manipulate accounting information for personal gain. This view assumes that stock price is a function of reported earnings and that executives manipulate accounting earnings to increase the value of their personal equity holdings. ${ }^{1}$ If this allegation is true and the economic cost of accounting manipulation is large, this idea has important implications for executive-compensation contract design and corporate monitoring by both internal and external parties.

Although at least ten recent studies have examined the relationship between equity incentives and various types of accounting irregularities, no conclusive set of results has emerged from this literature. Eight prior studies find evidence of a positive relationship, but even within this group the evidence is mixed with regard to which components of an executive's equity incentives (e.g., restricted stock, unvested options, and vested options) produce this association. Two additional studies do not find evidence of a relationship, even though they share similar proxies and samples with studies that do find a relationship.

\footnotetext{
${ }^{1}$ This view implicitly ignores (or considers as trivial) the effect of executive ethics, actions by monitors, and executives' expected costs associated with manipulation. This view also requires that the market is unable to distinguish between "true" and manipulated earnings.
} 
Most prior studies adopt a research design that relies heavily on assumptions about the functional form of the relationship between accounting irregularities and equity incentives (as well as whatever control variables are used in the study). Specifically, these studies match firms on the outcome variable of interest (e.g., a firm that experienced accounting fraud is matched with a firm that did not experience fraud during the same period) using a small number of variables such as firm size and industrial classification. Other potential confounding variables are "controlled" through their inclusion in an estimation equation that relates accounting irregularities to equity incentives. Although common in empirical research, this research design relies on a variety of restrictive and perhaps unrealistic assumptions to produce reliable inferences.

Prior studies have also tended to analyze a relatively small sample of firms that lie in the intersection of the Standard \& Poor's ExecuComp database and either Government Accountability Office (GAO) Financial Statement Restatements or U.S. Securities and Exchange Commission (SEC) Accounting and Auditing Enforcement Releases (AAERs). Since ExecuComp does not provide data for the majority of firms in the economy, it is possible that the results of prior studies are influenced by selection bias. ${ }^{2}$ Moreover, it is not clear whether small samples (e.g., between 50 and 200 observations) provide sufficient statistical power for an analysis of the determinants of a relatively rare event such as a major accounting manipulation. This uncertainty hinders the ability to draw inferences regarding the primary research hypothesis when a statistically significant relationship is not detected. Finally, prior studies have generally ignored the likely endogenous matching of executives with their observed compensation contracts and, thus, their observed level of equity incentives. Since this type of endogenous

\footnotetext{
${ }^{2}$ Studies using ExecuComp data may be prone to selection bias concerns, since ExecuComp focuses exclusively on firms listed in the Fortune 1500 (e.g., Cadman et al., 2006).
} 
matching is an important feature of the executive labor market, it is difficult to interpret prior results, because the reported parameter estimates are likely to be biased.

We draw inferences regarding the relationship between CEO equity incentives and accounting irregularities from a broad data set and use a research design that better addresses the potential confounds inherent in observational studies (Rosenbaum and Rubin, 1983; Rosenbaum, 2002). To reduce the potential for "overt bias," we employ a propensity-score matched-pair research design to join observations that are similar along a comprehensive set of firm- and manager-level dimensions. ${ }^{3}$ The propensity-score method forms matched pairs of CEO firmyears that have similar contracting environments but differing levels of CEO equity incentives. This approach alleviates misspecification that occurs when the research design assumes an incorrect functional form for the relationship between the variables of interest (including controls) and the outcome.

We also assess the sensitivity of our results to "hidden bias," or unobserved correlated omitted variables, using the bounding techniques developed by Rosenbaum (2002). This bounding approach provides insight into the likelihood that our results are confounded by explanations such as endogenous matching of CEOs and equity incentives on the basis of unobserved variables such as the level of CEO risk aversion. Thus, our research design relaxes the assumptions of the traditional matched-pairs approach and assesses the impact of omittedvariable and endogeneity concerns.

In contrast to most prior studies, we do not observe a positive relationship between CEO equity incentives and the incidence of accounting irregularities. Instead, our evidence suggests

\footnotetext{
${ }^{3}$ Rosenbaum (2002) defines overt bias as "one that can be seen in the data at hand," which means that it is bias that is related to observable variables. It can result from either omission of observable variables or from the specification of an improper functional form for the relationship between observable variables and the outcome variable of interest. In contrast, "hidden bias" is associated with the omission of unobservable variables (i.e., correlated omitted variables). We consider both types of bias in our analysis.
} 
that the level of CEO equity incentives has a modest negative relationship with the incidence of accounting irregularities. This result is more consistent with the notion that equity incentives reduce agency costs that arise with respect to financial reporting, than is the interpretation that equity incentives cause managers to manipulate reported earnings.

Although we provide only one substantive application, propensity-score methods can (and perhaps should) be applied to other empirical accounting studies in which the hypothesized causal variable is an endogenous choice by managers, boards of directors, or other similar parties. In particular, using propensity scores to generate matched pairs with maximum variation in the causal variable of interest while minimizing the variation in the controls is, in many cases, a superior econometric approach to matching on the outcome variable and relying on a linear or some other assumed functional form to control for confounding variables. Moreover, propensity-score methods also enable the researcher to explicitly quantify the sensitivity of the results for the primary causal variable to unobserved correlated omitted variables.

Section 2 of this paper reviews the prior literature examining the relationship between executive incentives and accounting irregularities. Section 3 describes the sample and our primary measurements. Section 4 discusses the propensity-score matched-pair research design and compares this approach with the regression research design that is common in prior studies. Section 5 presents our primary empirical results. Section 6 discusses sensitivity analyses. Section 7 provides concluding remarks. Finally, Appendix A includes basic methodological background regarding observational studies and Appendix B discusses the importance of functional form when selecting regression or matching approaches for inference.

\section{Prior Research}


At least ten recent studies (summarized in Table 1) examine the relationship between accounting irregularities and executives' equity incentives. These studies generally hypothesize that equity-based compensation and holdings provide incentives for managers to manipulate accounting numbers (e.g., Harris and Bromiley, 2007; Efendi, Srivastava, and Swanson, 2007; Bergstresser and Phillipon, 2006), perhaps to increase gains from pending insider sales (Cheng and Warfield, 2005). Harris and Bromiley (2007), for example, suggest that the likelihood of managerial impropriety rises with "the strength of inducements" and therefore test for a positive relationship between the probability of accounting misrepresentation and stock-option compensation. Few studies (e.g., O’Connor, Priem, Coombs, and Gilley, 2006; Burns and Kedia, 2006), however, explicitly consider the alternative possibility that equity incentives might instead lessen management's desire to manipulate accounting numbers by aligning managers' interests with those of shareholders.

Eight of the ten papers listed in Table 1 find some evidence that executives' equity incentives exhibit a positive statistical association with accounting manipulation. Although the results of these studies might be considered as a consensus for this research question, there is considerable variation across inferences presented within these papers. This lack of consistency occurs even though similar proxies for accounting manipulation and equity incentives are used and there is considerable cross-sectional and temporal overlap in their samples. For example, Johnson, Ryan, and Tian (2009) and Erickson, Hanlon, and Maydew (2006) both assess the relationship between the incidence of accounting fraud (identified using AAERs) and the equity portfolio delta computed for top firm executives. ${ }^{4}$ Although the two samples exhibit considerable overlap, Johnson, Ryan, and Tian (2009) report evidence of a strong positive association between

\footnotetext{
${ }^{4}$ Equity portfolio delta is the change in the (typically risk-neutral) dollar value of an executive's equity portfolio (stock, restricted stock, and stock-option holdings) for a $1 \%$ change in the price of the underlying stock.
} 
unrestricted equity holdings and the incidence of accounting fraud, while Erickson, Hanlon, and Maydew (2006) do not observe any statistical association. Similarly, Baber, Kang, and Liang (2007) and Harris and Bromiley (2006) both examine the relationship between equity incentives and the incidence of accounting restatements. Their samples differ in the number of observations but overlap completely in observation years. In spite of this overlap, the studies report surprisingly different results. Harris and Bromiley (2006) find a positive association between the incidence of accounting restatements and the ratio of option compensation to total compensation, while Baber, Kang, and Liang (2007) do not find a similar statistical association.

Some prior studies provide evidence of a positive association only for certain components of option-related holdings (e.g., Harris and Bromiley, 2006; Burns and Kedia, 2006; Efendi, Srivastava, and Swanson, 2007). Others provide evidence of a positive association for different equity components, such as unvested options and stock ownership (Cheng and Warfield, 2005), vested stock holdings (Johnson, Ryan, and Tian, 2009), and the entire equity portfolio (Bergstresser and Phillipon, 2006). Yet another study finds evidence of a positive association for option-related equity components only when conditioned on the Board of Directors' composition and compensation structure (O'Connor, Priem, Coombs, and Gilley, 2006). These inconsistencies highlight the difficulty in drawing general inferences regarding the association between equity incentives and accounting irregularities from prior research.

\section{Sample and Measurement Choice}


Our sample of CEO equity incentives, measured between 2001 and 2005, is obtained from a comprehensive database provided by Equilar, Inc. ${ }^{5}$ This database is similar to ExecuComp's in that it provides executive-compensation and equity-holdings data collected from annual proxy filings (DEF 14A) with the SEC. However, the Equilar data provides 3,634, 3,930, 4,043, 4,051, and 4,047 CEO-firm observations (in contrast with the roughly 1,500 CEO-firm observations available annually from ExecuComp) across fiscal years 2001 to 2005, respectively. ${ }^{6}$

It is difficult to construct an appropriate empirical measure for the incidence of accounting manipulation, since this managerial action is unobserved. Most empirical studies infer manipulation from observing "extreme" outcomes in which manipulation is likely to have occurred (e.g., incidences of accounting restatements and regulatory or legal action). One concern with this measurement method is that it incorrectly classifies firms that manipulate accounting but that are not identified for restatement or for regulatory or legal action. The potential for misclassification is a limitation of our study as well as of previous studies in this area.

To reduce the risk of misclassification, we consider three different types of "accounting irregularities." The first is financial restatements related to accounting manipulation. These data are obtained from Glass-Lewis \& Co., which comprehensively collects restatement information from SEC filings, press releases, and other public data. We identify accounting restatements between 2001 and 2005 that relate to perceived reporting manipulation classified as accounting fraud, an SEC investigation, a securities class action suit, improper reserve allowances, improper

\footnotetext{
${ }^{5}$ The period 2001-2005 overlaps with regulatory environment changes (e.g., Sarbanes-Oxley Act, Regulation FD, SEC Rule 10b5-1) that may affect inferences relative to those reported in studies that examine earlier periods. We assess the sensitivity of our inferences to time-period choice in Section 6.4.

${ }^{6}$ The total of 19,705 pooled observations is the maximum number of CEO-firm-years available from Equilar. Eliminating observations with missing analysis data yields 13,706 pre-match CEO-firm-year observations. Requiring one-year-ahead data yields 10,773 CEO-firm-year observations for the propensity-score estimation. The propensity-score matching algorithm yields a primary analysis sample of 9,118 CEO-firm-year observations $(4,559$ matched pairs).
} 
revenue recognition, or improper expense recognition. ${ }^{7}$ We code a restatement incident as the first fiscal year in which improper accounting occurred that subsequently necessitated a restatement. As shown in Table 2 (Panel A), we identify 464 restatement incidents $(3.4 \%$ of the total sample) across the time period covered in our analysis, with the most observations occurring during fiscal year 2004.

The second accounting irregularity we consider is whether the firm was accused of accounting manipulation in a class action lawsuit. We identify these firms in a database provided by Woodruff-Sawyer and Co. that records class action lawsuit damage periods between 2001 and 2005. The lawsuits allege disclosure or financial-statement earnings estimate improprieties, financial misrepresentation, failure to adhere to GAAP, or restatement of earnings. ${ }^{8}$ We code a lawsuit incident as the first fiscal year in which the firm is named in a lawsuit damage period. We identify 464 incidents of accounting-related lawsuit allegation periods (3.4\% of the total sample) across the time period, with the most observations occurring during fiscal year 2001 (Table 2, Panel A).

The final accounting irregularity we consider is whether the firm was accused of accounting manipulation in an AAER from the SEC. We identify these firms from the comprehensive AAER listing provided on the SEC website for allegation periods between 2001 and 2005 that allege earnings-estimate improprieties, financial misrepresentation, or failure to adhere to

\footnotetext{
${ }^{7}$ Revenue recognition restatements may result from changes in GAAP or GAAP enforcement (e.g., Staff Accounting Bulletin 101). We classify these restatements as "manipulation," since many GAAP enforcement changes resulted from regulatory perception that revenue was being misreported. For sensitivity, we also restrict our restatement sample to the subsample of Glass-Lewis restatements that note revenue recognition, expense recognition, or concerns over reserves and allowances (Palmrose et al., 2004) and also note a material weakness, a late filing, an auditor change, or a restatement via 8-K filing. Results for this restricted restatement sample are qualitatively similar to our reported results.

${ }^{8}$ Woodruff-Sawyer and Co. collects comprehensive class action lawsuit data to help estimate premiums for brokering directors and officers' liability insurance. A class action damage period is the period that precedes the lawsuit filing date during which the plaintiff alleges that damages (e.g., accounting manipulation) had occurred.
} 
GAAP. ${ }^{9}$ We code an AAER incident as the first fiscal year in which the SEC alleges that accounting manipulation occurred, as detailed in the Enforcement Release. Table 2 (Panel A) shows that there were only 157 incidents of accounting-related AAER allegation periods ( $1.2 \%$ of the total sample) across the time period, indicating that AAERs occur much less frequently than do both accounting restatements and accounting-related litigation. ${ }^{10}$

Consistent with prior literature (e.g., Core and Guay, 1999; Erickson, Hanlon, and Maydew, 2006; Burns and Kedia, 2006), we measure CEO equity incentives as the portfolio delta, defined as the (risk-neutral) dollar change in the CEO's equity portfolio value for a $1 \%$ change in the firm's stock price. The value of stock and restricted stock is assumed to change dollar-for-dollar with changes in the price of the underlying stock. The value of stock options is assumed to change according to the option's delta, which is the derivative of its Black-Scholes value with respect to the price of the underlying stock (Core and Guay, 2002). ${ }^{11}$

Since we are concerned with economically substantive differences in the level of equity incentives among executives, we partition equity incentives into five quintiles for our analyses. Using quintiles also allows us relax the assumption that $\mathrm{CEO}$ equity incentives have a monotonic

\footnotetext{
${ }^{9}$ We define an enforcement action allegation period as the period that precedes the AAER filing date during which the SEC alleges that accounting manipulation had occurred. For most AAER filings, the allegation period involves several years that well precede the AAER filing date. It is common, for example, to observe 2007-year filings that refer back to allegation windows that occur between 2001 and 2005.

${ }^{10}$ Untabulated results show that all three measures display a positive contemporaneous correlation. In particular, the Pearson correlation between (i) restatements and AAERs is 0.07, (ii) restatements and litigation is 0.10 , and (iii) AAERs and litigation is 0.21 . All three are highly statistically significant ( $p<0.001$ using a two-tailed test). There are $64 \mathrm{CEO}$-firm-year observations that experience both restatement and litigation events, 27 observations that experience both restatement and AAER events, 55 observations that experience both litigation and AAER events, and 13 observations that experience all three events contemporaneously.

${ }^{11}$ The parameters of the Black-Scholes formula are calculated as follows. Annualized volatility is calculated using continuously compounded monthly returns over the prior 36 months (with a minimum of 12 months of returns). The risk-free rate is calculated using interpolated interest rate on a Treasury note with the same maturity (to the closest month) as the remaining life of the option multiplied by 0.7 to account for the prevalence of early exercise. Dividend yield is calculated as the dividends paid over the past 12 months scaled by the stock price at the beginning of the month. This is essentially the same method described by Core and Guay (2002).
} 
association with accounting irregularities. ${ }^{12}$ Quintile rankings also exhibit better measurement properties than continuous incentive measurements do, since the empirical distribution of CEO portfolio deltas is right-skewed (Table 2, Panel B).

Figure 1 presents frequency histograms for both contemporaneous and one-year-ahead accounting irregularities partitioned by $\mathrm{CEO}$ equity-incentives quintile. Consistent with results from prior literature, Figure 1 provides some evidence of a positive (univariate) relationship between CEO equity incentives and the incidence of accounting irregularities, with the strongest monotonic pattern appearing for AAER and lawsuit outcomes. Rank correlations (untabulated) confirm that AAERs (coefficient $=0.023, p$-value $=0.0070)$ and lawsuits $($ coefficient $=0.052, p$ value $=<0.0001)$ have a statistically positive association with CEO equity incentives. However, equity incentives are correlated with many characteristics of executives' contracting environments that could also produce univariate patterns similar to those in Figure 1.

\section{Research Method}

Since a pure experiment with random assignment is typically infeasible, most empirical accounting studies are observational in nature. There is an extensive literature in econometrics and statistics that identifies conditions necessary to make causal statements in an observational study about the impact of the treatment variable (CEO equity incentives) on the outcome (accounting irregularities). We summarize the theoretical framework in Appendix A.

Prior research typically selects a set of firms with an observed accounting irregularity and then obtains another firm without an irregularity that is matched on year, industry, and size. ${ }^{13}$

\footnotetext{
${ }^{12}$ Relaxing the monotonicity assumption also allows us to better isolate the location of any association between equity incentives and accounting irregularities on the support of the equity-incentives distribution. In the extreme case, there could be a positive association at one end (e.g., high incentives) and a negative association at the other end (e.g., low incentives), and these separate effects would be obscured in a model that imposes monotonicity in the relationship.
} 
The effect of incentives on the frequency of accounting irregularities is then inferred from the estimated coefficient on equity incentives. Other variables are "controlled" through their inclusion in the regression estimation.

The validity of this common research design relies on several critical assumptions. As discussed more fully in Appendix B, the partial-matched econometric method produces unbiased parameter estimates only if there is an identical functional relationship between the control variables and the outcome variable for each level of treatment. ${ }^{14}$ If instead the true relationship between the controls and the outcome variable either differs across levels of treatment or is inconsistent with the functional form imposed by the research design, the partial-matched econometric method will produce biased parameter estimates. Further, this misspecification increases the likelihood of drawing an erroneous conclusion about the existence of a causal effect of the treatment.

We adopt an alternative approach that is more robust to misspecification of the functional form of the underlying relationship between equity incentives and accounting irregularities. Specifically, we use a matched-pair research design that matches a treatment firm with a control firm that is similar across all observable relevant variables. Our matching algorithm uses the common partial-match variables plus all other variables that would typically be included as control variables. Matching on these additional variables relaxes the assumption of a constant

\footnotetext{
${ }^{13}$ Most prior studies match on differences in the outcome rather than on differences in the treatment. The distinction between the two alternative research designs has important inferential implications, since only the latter isolates the relationship of interest. Because matching on the outcome does not remove variation in control variables, the research design implicitly searches for any cause(s) of an effect. In contrast, to the extent it is possible to achieve covariate balance, matching on the treatment removes variation in other potentially confounding variables to isolate the effect of a treatment of interest. Further, matching on the outcome has two key limitations. First, inferences from this design rely heavily on the assumed functional form of the relationship (see Appendix B). Second, this design may induce low power, since it does not ensure that variation remains in the treatment variable of interest (see Section 6.3). In contrast, matching on the treatment is analogous to a randomized experiment in which the randomized treatment assignment deliberately induces variation in treatment.

${ }^{14}$ Logistic regression, for example, assumes that a linear functional relationship exists between the log of the odds ratio and the observable predictor variables.
} 
functional relationship with the outcome variable and therefore is robust to misspecification of the functional form (see Appendix A).

\subsection{Implementation of the Propensity-Score Matched-Pairs Design}

Our matched-pair research design consists of five steps. First, we estimate an ordered logistic propensity-score model, which is the probability that an executive will receive a certain level of equity incentives (i.e., the treatment) conditional on observable features of the contracting environment. Second, we form matched pairs by identifying the pairings that result in observations with the smallest propensity-score differences (i.e., the most similar observed contracting environments) but the greatest difference in actual CEO equity incentives (i.e., the most dissimilar contracts). Third, we examine the covariate balance between the treatment and control samples and (if necessary) remove the most dissimilar matched pairs to achieve better control for potentially confounding factors. ${ }^{15}$ Fourth, we examine the relationship between equity incentives and accounting irregularities by assessing whether the frequency of accounting irregularities is significantly different between the treatment and control groups. Fifth, we estimate the sensitivity of reported results to potential hidden bias by relaxing the assumption that matched observations have an equal probability of receiving a certain level of treatment conditional on the observable contracting environment (Rosenbaum, 2002). The final step explicitly acknowledges that unobservable contracting characteristics can affect each executive's level of equity incentives (e.g., endogenous matching of executives and contracts on unobservable firm and CEO characteristics such as CEO risk aversion). This assessment

\footnotetext{
${ }^{15}$ It is important to note that this step is not ad hoc and does not induce estimation bias. This step simply identifies and then removes matched pairs for which the matching algorithm did not produce an effective covariate match (without using any information about the outcome variable). Removing these observations alleviates inference problems that are discussed in Appendix B.
} 
quantifies the potential impact of this confounding effect on the observed statistical association between the treatment variable and the outcome.

\subsubsection{Propensity-Score Model}

One problem with implementing a matched-pair research design is the difficulty of obtaining proper matches when each observation is characterized by many relevant dimensions (or covariates). As the number of dimensions increases, it becomes increasingly difficult to find pairs of observations that are similar along all of these dimensions. Rosenbaum and Rubin (1983) develop the propensity score as a way to address this dimensionality problem. In particular, the propensity score is the conditional probability of receiving some level of treatment given the observable covariates. ${ }^{16}$

The treatment of interest in this study is the level of CEO equity incentives, so we require a propensity-score model of the conditional probability of receiving a certain level of equity incentives given observable features of a CEO's contracting environment. Prior theoretical and empirical research suggests a number of economic and governance characteristics that are associated with the level of CEO equity incentives, and we draw on this literature to specify the propensity-score model. Demsetz and Lehn (1985), for example, suggest that larger firms and firms with greater monitoring difficulties will provide greater CEO incentives. Dechow and Sloan (1991) suggest that firms with CEO horizon problems will provide greater CEO equity incentives. Finally, Core et al. (1999) suggest that firm governance characteristics, in part, determine CEO equity incentives. Therefore, we include proxies for size (market capitalization), complexity (idiosyncratic risk), growth opportunities (market-to-book ratio), monitoring

\footnotetext{
${ }^{16}$ Rosenbaum and Rubin (1983) discuss the necessary conditions for matching on the propensity score (which is a scalar value) rather than matching on each of the individual covariates. One condition is that the outcome is independent of the treatment given the observed covariates. A second condition is that the propensity score cannot perfectly classify observations into the treatment or control groups. This is necessary to ensure that for each observation, there is a potential match that has a similar probability of receiving the treatment.
} 
(leverage), CEO horizon problems (CEO tenure), and firm-governance characteristics (e.g., the

number of directors, the number of activist shareholders) in the propensity-score estimation.

We estimate the following ordered logistic propensity-score model, annually, for the CEOs in

our sample:

$\operatorname{Pr}($ EqIncQuint $)=$

$\alpha_{k}$

$+\quad \beta_{1}$ Leverage $_{i}$

$\beta_{3} \quad \log (\text { Idiosyncrisk) })_{i} \quad+\quad \beta_{4} \quad$ MkttoBook $_{i}$

$\beta_{6}$ OutsideChmn $_{i}+\beta_{7}$ OutsideLdDir $_{i}$

$\beta_{9} \quad$ StaggeredBd

$\beta_{12} \quad$ PctFoundingDirs

$\beta_{15} \quad$ PctFinExpsAud

$\beta_{10} \quad$ PctOldOutsDirs

$\beta_{13} \quad$ OutsideDirHolds $s_{i t}$

$\beta_{18} \quad \log \left(1+\right.$ NumBlockhldrs $\left.s_{i}\right)$

$\beta_{16} \quad$ DirCompMix

$\beta_{19} \quad \log \left(1+\right.$ Activists $\left._{i}\right)$

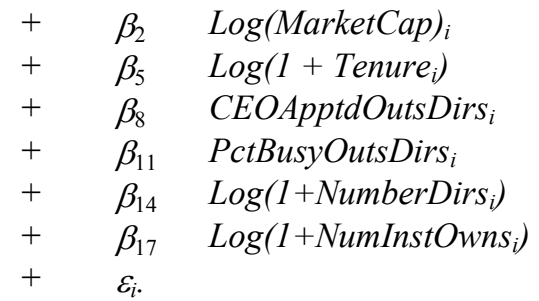

Variables are defined in Appendix C. The independent variables in equation (1) are measured in

the year prior to equity-incentives measurement, and descriptive statistics for these variables are

presented in Table 2 (Panel C). ${ }^{17}$

Table 3 reports the aggregated estimates of the annual ordered logistic propensity-score

regression of the level of equity incentives. ${ }^{18}$ The first column presents the average of the annual

coefficient estimates, and the second column reports an aggregated $z$-statistic. ${ }^{19}$ The final two

\footnotetext{
${ }^{17}$ Although we select the predictor variables in equation (1) based on prior research, we acknowledge that this choice process is somewhat arbitrary. An alternative research design would be to include only the traditional economic determinants of $\mathrm{CEO}$ incentives, as opposed to also including corporate governance variables. We include the governance variables because prior research shows that they are important determinants of the level of equity incentives (e.g., Core et al., 1999). In addition, if the propensity score only uses economic determinants, there is a high likelihood that the resulting matches will not be balanced with respect to the governance variables. This would result in an identification problem which would make it difficult to determine whether the accounting irregularities are caused by differences in the level of equity incentives, corporate governance, or both.

${ }^{18}$ In untabulated sensitivity analyses, we include two-digit SIC code as an additional propensity score estimation covariate. We also alter the algorithm to require matching from firms with the same two-digit SIC code. Both procedures produce fewer matches and modestly worse covariate balance across the treatment and control samples, but neither alters our primary inferences.

19 The aggregated $z$-statistic is calculated as the sum of the individual annual $z$-statistics divided by the square root of the number of years for which the propensity score model is estimated. The construction of this aggregate zstatistic assumes that each of the annual estimates is independent. However, the significance of either the individual or aggregated results presented in Table 3 does not affect our primary analysis of the relationship between equity incentives and accounting irregularities since matched pairs are formed annually based on the respective propensity score model.
} 
columns report the number of years in which the sign of each annual coefficient estimate is positive and negative, respectively.

Our results are generally consistent with prior research, in that we find that CEO equity incentives are greater at larger firms, firms with growth opportunities, and firms with longertenured CEOs. In addition, we find that equity incentives are lower at firms with stronger monitoring (e.g., outside chairman, lead director, number of institutional shareholders, and number of activist shareholders). We also observe that equity incentives exhibit a positive association with the percentage of the outside directors appointed by the CEO, the percentage of founders on the board, the percentage of shares held by the outside directors, and the degree to which equity incentives are used to compensate outside directors. Finally, Table 3 indicates that the propensity-score model has reasonable explanatory power $\left(\operatorname{Adj}\right.$. Pseudo- $\left.R^{2}=27.3 \%\right)$. This is important, since a propensity score with very low explanatory power effectively induces random matching, which increases the likelihood that inferences will be confounded by correlated omitted variables.

\subsubsection{Matching Algorithm}

In the case where a binary treatment is present (i.e., treatment or no treatment), matched pairs are formed by selecting an observation that received the treatment and selecting another observation with the closest propensity score that did not receive the treatment. Since we use CEO equity-incentive quintiles as our treatment, matching becomes an optimization problem of minimizing a function of the aggregate distances between the propensity scores of the matched pairs. We follow the approach outlined in Lu et al. (2001) and simultaneously minimize the difference between propensity scores and maximize the difference between equity-incentive levels with the following distance metric: 


$$
\begin{array}{cc}
\Delta_{i, j}=\frac{\left(\text { PScore }_{i}-\text { PScore }_{j}\right)^{2}}{\left(\delta_{i}-\delta_{j}\right)^{2}} & \text { if } \delta_{i} \neq \delta_{j} \\
\Delta_{i, j}= & \text { if } \delta_{i}=\delta_{j},
\end{array}
$$

PScore is the propensity score computed from equation (1), $\delta$ is each observation's equityincentive quintile, and $i, j$ index the individual observations. ${ }^{20}$ We then use a nonbipartite algorithm to identify, across all possible permutations, the minimum sum of pairwise distances, $\sum \Delta_{i, j}$ for $i \neq j$, where each observation is paired with another and observations can be used only once for matching (i.e., matching without replacement). ${ }^{21}$ In particular, we employ the nonbipartite matching algorithm suggested by Derigs (1988), which is an "optimal" algorithm in the sense that it considers the potential distances between other matched pairs when forming a particular matched pair (Lu et al., 2001).

The distribution of matched pairs according to their pairwise equity-incentive quintiles is presented in Table 4. The columns indicate the quintile of the treatment observation in each matched pair, while the rows indicate the quintile of its control counterpart. For example, the $(3,5)$ element of the matrix is 404 , which indicates that there are 404 matched pairs for which the treatment is in the highest quintile of equity incentives (i.e., five) and the control is in the middle quintile of equity incentives (i.e., three). The diagonal elements are all zero, since we preclude matches with identical equity-incentive levels. Not surprisingly, most matched pairs $(72.36 \%)$ lie immediately off the diagonal, where the difference in the quintile rank of incentives between the treatment and control is one. Only $4.96 \%$ of the paired observations have a difference of at

\footnotetext{
${ }^{20}$ The distance metric can be generalized to the case where the treatment variable (i.e., denominator) is continuous. See Hirano and Imbens (2004) for a theoretical discussion and Armstrong, Ittner, and Larcker (2009) and Armstrong, Blouin, and Larcker (2009) for examples of implementing this approach.

${ }^{21}$ It is not clear whether prior studies match with or without replacement. If matching is done with replacement and the same firm is included in multiple matches, it is necessary to adjust (increase) the standard error used for statistical tests. Depending on the correlation across matches, this adjustment can be quite large. In general, the distinction between matching with and without replacement represents a tradeoff of efficiency versus bias.
} 
least three quintiles. This result indicates that CEOs with similar contracting environments tend to have similar levels of equity incentives and that the propensity-score estimation method reasonably predicts CEO equity-incentive levels.

\subsubsection{Covariate Balance Between Treatment and Control Samples}

Covariate balance is achieved if both the treatment and control groups appear similar along their observable dimensions except for their level of equity incentives. An adequate degree of covariate balance is necessary to properly account for the confounding effects of the observed control variables used to match the observations. If balance is not achieved, it may be necessary to remove the matched pairs that contributed to the imbalance. ${ }^{22}$ Examining covariate balance is important also because it can highlight potential identification problems. If there is a variable for which it is not possible to achieve adequate balance across the treatment and control groups, the treatment effect cannot be identified by the research design. For example, assume that the treatment group (CEOs with high equity incentives) always consists of larger firms than the control group (CEOs with low equity incentives). This setting will produce an identification problem, because any observed difference in outcome between the treatment and control groups cannot be uniquely attributed to either the treatment or to firm size.

To assess covariate balance between the treatment and control groups, we report both a parametric $t$-test of the difference in means and a nonparametric Kolmogorov-Smirnov $(K S)$ test of the difference between two distributions. ${ }^{23}$ Table 5 presents the means and medians of the

\footnotetext{
${ }^{22}$ Although removing observations can improve covariate balance, it may also restrict the range over which the researcher can make statements about the relationship between the treatment and the outcome of interest. It is only appropriate to draw inferences from within the overlapping support of the distributions. Inferences from outside this range are based on extrapolation and rely on an assumption about the functional form of the relationship outside this range (e.g., linearity).

${ }^{23}$ The $t$-test assumes normality of the data, while the two-sample Kolmogorov-Smirnov test is a non-parametric test and is sensitive to differences in both the location and shape of the empirical distributions of the samples. Following Sekhon (2007), we bootstrap the $K S$ test statistic with 2,000 bootstrap samples because "the bootstrapped Kolmogorov-Smirnov test, unlike the standard test, provides correct coverage even when there are point masses in
} 
treatment and control groups along with the $p$-values (two-tailed) for both the $t$-test and the $K S$ test. The $p$-values for the $t$-test and $K S$-test indicate that the matching algorithm was successful in achieving balance for most covariates. In particular, 19 of the $20 \mathrm{t}$-tests and 13 of the $20 \mathrm{KS}$ tests are not statistically significant ( $p>0.05$, two-tailed). Moreover, even in the cases in which the means and medians are statistically different, the economic differences between the treatment and control sample are very small. Statistical significance appears to occur because we have a relatively large sample size for these tests. These results suggest that the covariates are generally balanced across the treatment and control samples and that differences in these observed variables across the treatment and control groups are not likely to confound our estimates of the average treatment effect.

\section{Results}

\subsection{Primary Results}

Table 6 presents our primary results regarding the relationship between equity incentives and accounting irregularities. The formal statistical test of this relationship entails examining the discordant frequency of accounting irregularities that are associated with a particular treatment level. ${ }^{24,25}$ Accounting irregularities are counted for the first year in which an accounting-

the distributions being compared." This is important in our cases, since we include a number of dichotomous variables in our specification.

24 A pair of observations is concordant if each observation experiences the same outcome and discordant if each has a different outcome. We assess the significance between the number of concordant and discordant pairs using McNemar's (1947) $\chi^{2}$ statistic. With small samples, the McNemar's $\chi^{2}$ may be misleading and an exact cumulative binominal test should be used (Liddell, 1983). None of our inferences change when this exact test is used for evaluating the results in Table 6 .

${ }^{25}$ When it is not possible to achieve adequate covariate balance, an alternative approach is to form matched pairs with the propensity scores and then estimate a (conditional logistic) regression of the outcome as a function of treatment and the vector of control variables used in the propensity-score model (Ho et al., 2007). For sensitivity, we estimate conditional logistic regressions of accounting irregularities on the level of equity incentives and the controls that were used in the propensity-score estimation regression. Results (untabulated) are similar to those reported in Table 6; an outcome that is not surprising given the high degree of covariate balance achieved through first-stage matching. 
manipulation-related restatement is observed (Panel A), in which the firm is involved in a class action damage period (Panel B), or in which the firm is involved in an AAER damage period (Panel C). ${ }^{26}$

For each accounting irregularity, we present the results for both the contemporaneous and one-year-ahead relationship in three ways that take advantage of different amounts of information about the equity-incentives quintile of the treatment and control observation. First, we present results according to each possible pairing of equity-incentives quintile. Since there are five levels of equity incentives and we preclude a matched pair from having an identical level of equity incentives, there are ten possible combinations for each pair. This is the finest level of aggregation and preserves information about both the magnitude of the difference in the level of equity incentives and the location on the support of the equity-incentive distribution. Second, we group matched pairs according to the difference in equity-incentive quintiles between the treatment and control observations. This is a more coarse level of aggregation that preserves information about the difference in the level of equity incentives between the treatment and control observations but ignores information about their location on the support of the equityincentive distribution (e.g., a 5-3 quintile pair is treated the same as a 3-1 quintile pair because they both represent a difference of two quintiles between the treatment and control observations). Third, we pool all of the treatment and control observations and look for differences in the incidence of accounting irregularities between these two groups. This is the coarsest level of aggregation and ignores information about both the magnitude and location of the equity incentives. It considers only whether each observation in a matched pair has a higher or lower level of equity incentives. It does, however, have the benefit of maximizing the sample size,

\footnotetext{
${ }^{26}$ It is extremely rare for the same firm to appear in multiple discordant pairs. Therefore, correlation across observations from the same firm is unlikely to induce inference problems. Cross-sectional correlation is also not likely to induce inference problems, since treatment and control firms are matched in the same year.
} 
which increases the power of the test. To help assess the economic magnitude of incentive-level differences between the treatment and control groups, Table 6 also reports $\$$ Incent, which is the median portfolio delta for matched observations reported in the frequency cells. ${ }^{27}$

The results presented in Table 6 (Panel A) do not support the notion that higher equityincentive levels are associated with a greater incidence of accounting-related restatements. There are no instances of statistically larger restatement frequencies for treatment observations relative to control observations for any comparison. In contrast, we find some modest evidence consistent with the alternative explanation that equity incentives align managers' interests with those of shareholders. When there is a difference of one between the level of equity incentives in the treatment and control observations (i.e., DiffEqIncQuint $=1)$, there are $34(=119-153)$ more restatement incidents observed in the subsequent year $(p$-value $=0.045)$ for the firms with lower incentives (control firms) relative to the firms with higher incentives (treatment firms).

The results presented in Table 6 (Panel B) are similar to those in Panel A. We find no evidence that higher equity incentives are associated with a higher frequency of accountingrelated lawsuits. Instead, the pooled results for contemporaneous and one-year-ahead lawsuit frequency show more lawsuits for firms with lower incentives relative to firms with higher incentives ( $p$-value $=0.018$ and 0.025 , respectively). Looking forward one year, there is also evidence of fewer lawsuits at firms with lower equity incentives, where the equity incentives differ by two quintiles ( $p$-value 0.031$)$.

Finally, the results in Table 6 (Panel C), which relates to AAER damage periods, are consistent with those in Panels A and B. There is no evidence of a positive association between

\footnotetext{
${ }^{27}$ Table 6 reports \$Incent only when the difference between equity incentives quintiles is equal to one (and for pooled data), since this reflects the minimum equity-incentive distance and there is sufficient sample size for tests of median differences. All treatment-control \$Incent differences are statistically significant $(\mathrm{p}<0.01$, two-tailed) using a Kruskal-Wallis test.
} 
equity incentives and the incidence of AAER damage periods. However, there is evidence that higher equity incentives are associated with a lower incidence of AAERs. Specifically, when observations are pooled and when the difference in the level of equity incentives is one or two, there are more contemporaneous AAERs for the control firms relative to the treatment firms $(p$ value $=0.010,0.070$, and 0.066 , respectively)

Overall, the results in Table 6 do not provide evidence of a positive association between equity incentives and the frequency of accounting irregularities. In contrast, there is a modest negative association between incentives and the frequency of accounting irregularities. Thus, our results are more consistent with incentive alignment rather than with managerial rent extraction.

\subsection{Hidden Bias Sensitivity}

It is well known that the results of non-experimental empirical studies are susceptible to hidden bias caused by the omission of an unobservable yet relevant variable (i.e., a correlated omitted variable). Surprisingly, few empirical accounting studies attempt to quantify the potential effects of hidden bias on their primary conclusions. We use a bounding approach outlined by Rosenbaum (2002) and DiPrete and Gangl (2004) to assess the sensitivity of our inferences to potential hidden bias that might exist, because of endogenous matching of executives and equity-incentive contracts and other similar factors. ${ }^{28}$ Rosenbaum (2002) and DiPrete and Gangl (2004) note that although propensity-score matching effectively alleviates

\footnotetext{
${ }^{28}$ It is quite likely that hidden bias is present in this study, as well as the papers summarized in Table 1, because of selection on unobservables (Heckman and Hotz, 1989). Selection on unobservables occurs when it is not possible to observe all of the covariates that affect a decision maker's selection. For example, if certain firms use contracts with a high level of equity incentives to select more risk-seeking executives and more risk-seeking executives choose firms that offer riskier compensation packages (with higher equity incentives), there is endogenous matching on executive risk aversion. If risk-seeking executives are also more likely to manipulate accounting reports, this endogenous matching on an unobservable variable (i.e., the degree of CEO risk aversion) would induce hidden bias in our results, and we might misattribute an difference in the frequency of accounting irregularities to differences in the level of CEO equity incentives, rather than to differences in the degree of CEO risk aversion.
} 
overt bias relating to observable covariates, it does not remove hidden bias that might arise from unobserved covariates. Both studies outline an approach to identify the limits at which an unobservable confounding variable would alter inferences that can be drawn from an analysis based on only the observed variables.

Rosenbaum (2002) shows that hidden bias exists if two observations (denoted $i$ and $j$ ) have the same observed $x$ covariates but different probabilities (denoted as $\pi$ ) of receiving treatment because of some unobserved factor. In the case of a binary treatment, the odds that each observation, $i$ and $j$, receive treatment are $\pi_{i} /\left(1-\pi_{i}\right)$ and $\pi_{j} /\left(1-\pi_{j}\right)$, respectively. Since these two observations look similar across their observable covariates $x$, they would be paired by a matching algorithm to minimize overt bias. If the odds ratio (denoted as $\Gamma$ by Rosenbaum, 2002) does not equal one, each observation in a matched pair has an unequal probability of receiving treatment and there is a hidden bias inherent in the analysis. Rosenbaum (2002) shows that relaxing the assumption that $\Gamma=1$ (i.e., that two observations with identical observable covariates have an identical probability of receiving treatment) can be used to compute significance test boundaries under different assumptions about the strength of the hidden bias that is necessary to alter the qualitative inferences from a study.

We assess the sensitivity of observed statistically significant results by estimating the boundary $\Gamma$ values for cases in which the McNemar's test $p$-values exceed 0.10 (two-tailed). Specifically, in the cases in which there is a statistically significant difference between the outcomes of the treatment and control groups, we calculate the value of $\Gamma$ (or the odds ratio) at which a significance level of 0.10 would be obtained. These $\Gamma$ values allow us to quantify the amount of hidden bias necessary to invalidate the statistical significance that results from the 
assumption that two observations with identical propensity scores have an equal probability of receiving the treatment.

These boundary values are presented (where applicable) in Table 6. We find that there are several cases in which a statistically significant relationship is observed, yet only a small $\Gamma$ value is needed to reduce the statistical significance of the result. ${ }^{29}$ This finding suggests that these results are very sensitive to hidden bias and should be interpreted with caution. For example, consider the case of one-year-ahead restatements related to accounting manipulation for the 5-4 incentive quintile pairs presented in Panel A of Table 6. In this case, there are 55 restatements observed from the control group and 31 restatements observed from the treatment group. Although this difference is statistically significant ( $p$-value $=0.013$ ), a value of $\Gamma=1.37$ would result in a $p$-value of 0.10 . Therefore, this result would be marginally significant ( $p$-value $=$ 0.10 ) if control firms were actually 1.37 times more (rather than equally) likely to receive lower equity incentives than treatment firms, after conditioning on observable features of the contracting environment using the propensity score.

There are also cases in which the observed results are much less sensitive to hidden bias. For example, Panel $\mathrm{C}$ of Table 6 reports nine AAER incidents for the fifth incentive quintile and 29 AAER incidents for the fourth incentive quintile in the contemporaneous AAER estimation ( $p$ value $=0.002)$. For this comparison, we find that $\Gamma=6.26$, which provides robust support for the inference that very high levels of CEO equity incentives minimize AAER frequency.

\footnotetext{
${ }^{29}$ To our knowledge, no objective benchmark exists to determine whether a given $\Gamma$ is "large" or "small." Therefore, the designation is subjective and depends on the reader's prior beliefs as to the degree of endogenous selection on unobservable factors (e.g., risk-aversion, talent, productivity) in CEO contracting. Larger values of $\Gamma$, however, provide greater confidence that results are robust to hidden bias. Smaller values of $\Gamma$ indicate that results are sensitive to hidden bias, thereby confounding inferences from the analysis. Future research should consider identifying threshold $\Gamma$ values, perhaps through gathering and evaluating an empirical distribution of $\Gamma$ values implicit in other studies. An alternative approach outlined by Altonji, Elder, and Taber (2005) is to express the degree of selection on unobservable factors relative to the degree of selection on observable factors that would be necessary to alter the statistical significance of the results.
} 
Overall, there is mixed evidence on whether results are robust to hidden bias. The most robust results occur in the higher quintiles of the equity-incentive distribution. As discussed above, these results also provide some evidence of a negative association between incentives and irregularities. Thus, the results that appear least sensitive to potential hidden bias are those that are consistent with an incentive-alignment explanation.

\section{Sensitivity Analyses}

\subsection{Proxy for CEO Equity Incentives}

It is possible that our proxy for equity incentives does not adequately measure the degree to which CEOs' utility is sensitive to changes in firm value. To assess the sensitivity of our results to our choice of equity-incentive proxy, we consider an alternative equity-incentive measure, EqCompMix. This measure is computed as the ratio of the risk-neutral dollar value of options plus restricted stock compensation to the risk-neutral value of total annual compensation (i.e., stock options, restricted stock, salary, bonus, and target long-term incentive-plan payouts). This (or a similar) incentive measure has been used in prior studies (e.g., Erickson, Hanlon, and Maydew 2007; Baber et al. 2007). In addition, compensation consultants commonly use equity mix in their recommendations to the board concerning executive compensation, and it may be a suitable alternative proxy for managerial incentives. After re-estimating the propensity-score model, matching algorithm, and primary tests, we find results (untabulated) to be generally similar to those reported in Table 6 .

\subsection{Equilar Versus ExecuComp Sample}

It is possible that our results are sensitive to sample selection because prior studies generally use data from larger and more mature firms that comprise the ExecuComp database. To evaluate 
this possibility, we re-estimate our results after constraining the sample to the subset of Equilar firms that also appear in the ExecuComp database. Our results (not tabulated) are consistent with those reported in Table 6.

\subsection{Econometric Approach}

Since the propensity-score matched-pair research design is quite different from the more traditional outcome-matched logistic regression, it is instructive to examine the sensitivity of our results to the choice of econometric approach. In Table 7 (Panel A), we report conditional logistic estimates from an outcome-matched sample. This sample was generated by matching (without replacement) firms with an accounting irregularity to firms without an accounting irregularity by year, two-digit SIC code, and total assets. The remaining variables from the propensity-score estimation (see Table 3 ) are included as controls. In contrast to the propensityscore results in Table 6, we find little statistically significant evidence of an association between accounting irregularities and equity incentives. ${ }^{30}$

To explore the sensitivity of our results further, Table 7 (Panel B) provides comparative results of the covariate balance obtained from propensity-score matching with those obtained from standard partial outcome-based matching. Although it is difficult to make direct comparisons with prior studies because of differences in sample composition and sample size, these results show that standard partial outcome-matching generally does not achieve balance for Leverage and Log(Idiosyncrisk) and often does not achieve balance for MkttoBook. In contrast, propensity-score matching appears to achieve balance for Leverage and yields generally smaller median differences for Log(Idiosyncrisk) and MkttoBook across samples. These results at least

\footnotetext{
${ }^{30}$ The only statistically significant difference is observed for one-year-ahead AAERs for which the estimated coefficient for equity quintile three is smaller than both the estimated coefficients for equity quintiles two and four. These results are mixed and are inconsistent with results in Table 6.
} 
suggest the possibility that the difference in results between Table 6 and Table 7 is related to the absence of covariate balance in the outcome-matched sample.

Equally important, covariate balance comparisons clearly show that propensity-score matching induces considerably more variation in the primary variable of interest, PortDelta. This is an important distinction, because increasing variation in the treatment variable will generate more powerful tests of the relationship between equity incentives and accounting irregularities.

\subsection{Time Period}

To assess the sensitivity of our results to alternative (earlier) time periods, we compare the results produced by standard partial outcome-matched logistic regression and the propensity score using the $A A E R$ sample in Erickson, Hanlon, and Maydew (2006). In this test, we examine the association between contemporaneous $A A E R s$ and the level of equity incentives. Following Erickson, Hanlon, and Maydew (2006), each $A A E R$ firm is matched to two firms without an AAER from the same year, two-digit SIC code, and similar total assets. Although Hosmer and Lemeshow (2000) show that conditional logistic regression is more appropriate when the sample if formed by matching on both the dependent and independent variables, we report the results for both standard logistic and conditional logistic estimation in Table $8 .^{31}$ We include control variables used by Erickson, Hanlon, and Maydew (2006) in this estimation.

\footnotetext{
${ }^{31}$ Accounting researchers often cite Maddala (1991) to justify estimation methods regarding limited dependent variables. In limited dependent variable regressions (e.g., logit or probit) in which observations are matched based on outcome alone, Maddala (1991) shows that bias is observed only in the intercept. Therefore, in this specific setting, one can draw unbiased inferences from non-intercept coefficients and can correct for the bias in the intercept (e.g., King and Zeng, 2001). Hosmer and Lemeshow (2000) show, however, that conditional logistic regression is required to produce appropriate inferences in cases in which observations are matched based on outcome and on selected control variables. In this specific setting, conditional logistic regression is necessary to account for the lack of independence between matched pairs in the sample, because pair component observations are not randomly sampled. When Maddala (1991, p. 790) states that the conditional logit “... is not relevant for the problems in accounting that we are dealing with," he is not considering cases in which the sample is formed by matching on both the dependent and selected independent variables..
} 
Consistent with Erickson, Hanlon, and Maydew (2006), we do not observe evidence of a relationship between the incidence of AAERs and the level of CEO equity incentives from estimates produced by standard logistic regression. However, conditional logistic regression provides some evidence of a positive association between the incidence of AAERs and the level of CEO equity incentives. The association is most pronounced for CEOs in the highest incentive quintile and is more consistent with results from several prior studies (Table 1). This finding also illustrates that inferences from a matched sample are sensitive to the choice of standard or conditional logistic estimation. ${ }^{32}$

Finally, we estimate the results from a propensity-score matched-pair design within this sample. ${ }^{33}$ Similar to the conditional logistic regression results, Table 8 (Panel B) reports evidence of a positive association between the incidence of $A A E R s$ and the level of $\mathrm{CEO}$ equity incentives at the highest level of the equity-incentive distribution. However, in contrast to conditional logistic results in Table 8 (Panel A), Panel B also reports evidence of a negative association between the incidence of AAERs and the level of CEO equity incentives at the lowest level of the equity-incentive distribution. $\Gamma$ values reported in Panel B indicate that the positive association observed at the upper end of the equity-incentive distribution is considerably more sensitive to potential hidden bias relative to the negative association observed at the lower end of the equity-incentive distribution.

There are two observations worth noting in this analysis. First, results are sensitive to research design choice and appear to be sensitive to the time period selected. Second, a non-

\footnotetext{
${ }^{32}$ Although we followed the methods used by Erickson, Hanlon, and Maydew (2006) to select our control sample, our control sample may differ from theirs. Thus, we cannot make a direct comparison between the results in Table 8 and those in Erickson, Hanlon, and Maydew (2006).

${ }^{33}$ The CEO incentive propensity score is estimated as a function of the regressors reported in Erickson, Hanlon, and Maydew (2006). Specifically, EqIncQuint $=\beta_{1}+\beta_{2} C E O=C H A I R+\beta_{3} N U M M T G S+\beta_{4}$ FINANCING $+\beta_{5}$ LEVERAGE $+\beta_{6}$ MARKET VALUE OF EQUITY $+\beta_{7}$ ALTMAN'S Z $+\beta_{8}$ BOOK TO MARKET $+\beta_{9}$ EARNINGS TO PRICE $+\beta_{10}$ RET ON ASSETS $+\beta_{11}$ SALES GROWTH $+\beta_{12}$ AGE OF FIRM $+\beta_{13}$ M\&A IN FIRST YEAR OF FRAUD $+\beta_{14}$ STOCK VOLATILITY $+\beta_{15}$ CEO TENURE $+\beta_{16}$ MISSING CEO TENURE $+\varepsilon_{i}$.
} 
monotonic relationship may exist between equity incentives and accounting irregularities. Therefore, it is difficult assess the relationship between equity incentives and accounting irregularities without considering research design choices that relax assumptions regarding the functional form linking treatment and control variables to the outcome.

\section{Conclusion}

The widespread use of "high-powered" equity incentives for CEOs and other top executives has generated interest in assessing whether these incentives align managers' interests with those of shareholders or whether they instead induce managers to manipulate accounting information for personal gain. A number of studies have examined this question, but their evidence is quite mixed regarding the relationship between equity incentives and various accounting irregularities. This paper examines this research question using a larger sample that is more representative of the economy and an econometric approach that better alleviates overt bias and provides an assessment of hidden bias.

Using a propensity-score matched-pair research design that is robust to misspecification of the underlying functional form that confounds the traditional logistic regression approaches, we find little evidence of a positive relationship between CEO equity incentives and the incidence of accounting-related restatements, shareholder lawsuits alleging accounting manipulation, and AAERs. If anything, our results suggest that higher equity-based compensation and holdings may actually reduce the incidence of improper financial reporting. Specifically, we find some evidence that firms at which the CEO has greater equity incentives have a lower frequency of accounting irregularities than do firms with similar contracting environments at which the CEO has a relatively lower level of equity incentives. 
Unlike most prior research, our results are most consistent with the notion that equity incentives play a role in aligning managers' interests with those of shareholders with regard to financial reporting. In sensitivity analyses, we find results that are similar when we use CEO equity mix (rather than portfolio delta) and when we constrain our sample to ExecuComp (rather than Equilar) firms.

Results generated with a propensity-score matched-pair research design can be quite different from those produced using standard and conditional logistic regression. Since the propensityscore approach is robust to the functional form linking control variables to the outcome, propensity-score results provide a better basis for statistical inference about the effect of the treatment in the absence of precise knowledge about the underlying structural relationship among the variables of interest. Moreover, the propensity-score approach allows for an explicit assessment for the sensitivity of the results to hidden bias (e.g., correlated omitted variables). Finally, there seems to be a temporal aspect for this research question, and this aspect may account for some of the differences between our results and those of prior research.

One important question that we do not answer is what, if not equity incentives, compels managers to engage in accounting manipulation. It would be useful for future research to develop and estimate structural models of managerial decisions regarding accounting manipulation. At this point, we do not know why executives engage in illegal and unethical behavior that can result in substantial legal and human-capital costs (e.g., Armstrong and Larcker, 2009). To gain further insight into this question, future research might consider behavioral explanations in addition to traditional economic or agency rationalizations. Manipulative behavior may result from social influence, where other firms, for example, manipulate accounting and thus allow executives to infer that this behavior is "legitimate." 
Alternatively, this behavior may be a function of lax ethical norms in the firm or the personal characteristics of executives engaged in accounting irregularities (e.g., Chatterjee and Hambrick, 2008). Research in this direction would be likely to enhance our understanding of the accounting irregularities.

Finally, propensity-score methods should be considered for future empirical accounting research in which the hypothesized causal variable is an endogenous choice (except, perhaps, in settings in which the outcome variable is very costly to collect). In particular, researchers should use propensity-score methods to generate matched pairs that induce maximum variation in the causal variable of interest (i.e., a full sample match). This approach is consistent with fundamental research in econometrics and statistics and is an arguably superior econometric approach to matching on the outcome variable and relying on a regression model to control for confounding variables (i.e., a partial match). Future research should also consider bounding methods to explicitly quantify the sensitivity of the results for the primary causal variable to unobserved correlated omitted variables. This will provide readers with the necessary information to assess the extent to which reported results are robust to correlated omitted variable and endogeneity concerns. 


\section{References}

AGRAWAL, A., and S. CHADHA. "Corporate Governance and Accounting Scandals." Journal of Law \& Economics 48 (2005): 371-406.

ALTONJI, J. G., T. E. ELDER, and C. R. TABER. "Selection on Observed and Unobserved Variables: Assessing the Effectiveness of Catholic Schools." Journal of Political Economy 113 (2005), 151-184.

ARMSTRONG, C., and D. LARCKER. "Discussion of 'The Impact of the Options Backdating Scandal on Shareholders' and 'Taxes and the Backdating of Stock Option Exercise Dates." Journal of Accounting and Economics, 47 (2009): 50-58.

ARMSTRONG, C., J. BLOUIN, and D. LARCKER. "The Incentives for Tax Planning." Working paper, the Wharton School at the University of Pennsylvania, 2009.

ARMSTRONG, C., C. D. ITTNER, and D. LARCKER. "Economic Characteristics, Corporate Governance, and the Influence of Compensation Consultants on Executive Pay Levels." Working paper, the Wharton School at the University of Pennsylvania, 2009.

BABER, W., S. KANG, and L. LIANG. "Shareholder Rights, Corporate Governance, and Accounting Restatement.” Working paper, Georgetown University, 2007.

BEGSTRESSER, D., and T. PHILIPPON. "CEO Incentives and Earnings Management." Journal of Financial Economics 80 (2006): 511-529.

BLACK, F., and M. SCHOLES. "The Pricing of Options and Corporate Liabilities." Journal of Political Economy 81 (1973): 637-654.

BRICKLEY, J. A., J. L. COLES, and R. L. TERRY. "Outside Directors and the Adoption of Poison Pills." Journal of Financial Economics 35 (1994): 371-390.

BURNS, N., and S. KEDIA. "The Impact of Performance-Based Compensation on Misreporting." Journal of Financial Economics 79 (2006): 35-67.

CADMAN, B., S. KLASA, and S. MATSUNAGA. "Evidence on How Systematic Differences Between ExecuComp and Non-ExecuComp Firms Can Affect Empirical Research Results." Working paper, University of Oregon, 2006.

CHATTERJEE, A., and D. HAMBRICK. "It's All About Me: Narcissistic CEOs and Their Effects on Company Strategy and Performance." Administrative Science Quarterly 52 (2007): 351-386.

CHENG, Q., and T. D. WARFIELD. "Equity Incentives and Earnings Management." The Accounting Review 80 (2005): 441-476. 
CORE, J., R. HOLTHAUSEN, and D. LARCKER. "Corporate Governance, Chief Executive Officer Compensation, and Firm Performance." Journal of Financial Economics 51 (1999): 371-406.

CORE, J., and W. GUAY. "The Use of Equity Grants to Manage Optimal Equity Incentive Levels." Journal of Accounting \& Economics 28 (1999): 151-184.

CORE, J., and W. GUAY. "Estimating the Value of Employee Stock Option Portfolios and Their Sensitivities to Price and Volatility." Journal of Accounting Research 40 (2002): 613630.

CRAGG, S. G., and R. UHLER. "The Demand for Automobiles." Canadian Journal of Economics 3 (1970): 386-406.

CREMERS, M., and V. B. NAIR. “Governance Mechanisms and Equity Prices.” Journal of Finance 60 (2005): 2859-2894.

DECHOW, P., and R. SLOAN. "Executive Incentive and the Horizon Problem." Journal of Accounting \& Economics 14 (1991): 51-89.

DEMSETZ, H., and K. LEHN. "The Structure of Corporate Ownership: Causes and Consequences." Journal of Political Economy 83 (1985): 1155-1177.

DERIGS, U. "Solving Non-Bipartite Matching Problems Via Shortest Path Techniques." Annals of Operations Research 13 (1988): 225-261.

DIPRETE, T., and M. GANGL. “Assessing Bias in the Estimation of Causal Effects: Rosenbaum Bounds on Matching Estimators and Instrumental Variables Estimation With Imperfect Instruments." Sociological Methodology 34 (2004): 271-310.

EFENDI, J., A. SRIVASTAVA, and E. P. SWANSON. "Why Do Corporate Managers Misstate Financial Statements? The Role of Option Compensation and Other Factors." Journal of Financial Economics 85 (2007): 667-708.

ERICKSON, M., M. HANLON, and E. L. MAYDEW. "Is There a Link Between Executive Equity Incentives and Accounting Fraud?" Journal of Accounting Research 44 (2006): 113143.

GOLDFELD, S. M., and R. E. QUANDT. "The Estimation of Structural Shifts by Switching Regressions." Annals of Economic and Social Measurement 2 (1973): 475-485.

HARRIS, J., and P. BROMILEY. "Incentives to Cheat: The Influence of Executive Compensation and Firm Performance on Financial Misrepresentation." Organizational Science 18 (2007): 350-367. 
HECKMAN, J., and S. NAVARRO-LOZANO. "Using Matching, Instrumental Variables, and Control Functions to Estimate Economic Choice Models." The Review of Economics and Statistics 86 (2004): 30-57.

HECKMAN, J., and R. ROBB. "Using Longitudinal Data to Estimate Age, Period, and Cohort Effects in Earnings Equations." In Mason and Feinberg, eds., Cohort Analysis in Social Research Beyond the Identification Problem, Springer-Verlag, New York (1985).

HIRANO, K., and G. W. IMBENS. "The Propensity Score With Continuous Treatments." In Applied Bayesian Modeling and Causal Inference From Incomplete Data Perspectives, A. Gelman and X. L. Meng, eds., 73-84. West Sussex, England (2004).

HO, D. E., K. IMAI, G. KING, and E. A. STUART. "Matching as Nonparametric Preprocessing for Reducing Model Dependence in Parametric Causal Inference." Political Analysis 199 (2007): 1-38.

HOLLAND, P. "Statistics and Causal Inference (with discussion)." Journal of the American Statistical Association 81 (1986): 945-970.

HOSMER, D. W., and S. LEMESHOW. Applied Logistic Regression. John Wiley and Sons, New York (2000).

IMBENS, G. W. "Nonparametric Estimation of Average Treatment Effects Under Exogeneity: A Review." The Review of Economics and Statistics 86 (2004): 4-29.

JENSEN, M. C. "The Modern Industrial Revolution, Exit, and the Failure of Internal Control Systems." Journal of Finance 48 (1993): 831-880.

JIN, L. "CEO Compensation, Diversification, and Incentives." Journal of Financial Economics 66 (2002): 29-63.

JOHNSON, S. A., H. E. RYAN, and Y. S. TIAN. "Managerial Incentives and Corporate Fraud: The Sources of Incentives Matters." Review of Finance 13 (2009):115-145.

KARPOFF, J. M., D. S. LEE, and G. S. MARTIN. "The Cost to Firms of Cooking the Books." Journal of Financial \& Quantitative Analysis 43 (2008):581-612.

KING, G., and L. ZENG. "Logistic Regression in Rare Events Data.” Political Analysis 9 (2001): 137-163.

KLEIN, A. "Firm Performance and Board Committee Structure." Journal of Law \& Economics 41 (1998): 275-303.

LARCKER D., S. RICHARDSON, and I. TUNA. "Corporate Governance, Accounting Outcomes, and Organizational Performance." The Accounting Review 82 (2007): 963-1008. 
LIDDELL, F. "Simplified Exact Analysis of Case-Referent Studies: Match Pairs; Dichotomous Exposure." Journal of Epidemiology and Community Health 37 (1983): 82-84.

LU, B., E. ZANUTOO, R. HORNIK, and P. R. ROSENBAUM. "Matching With Doses in an Observational Study of a Media Campaign Against Drug Use." Journal of the American Statistical Association 96 (2001): 1245-1253.

MADDALA, G. S. "A Perspective on the Use of Limited-Dependent and Qualitative Variable Models in Accounting Research." The Accounting Review 66 (1991): 788-807.

MCFADDEN, D. "Statistical Tools.” Working paper, University of California, Berkeley, 2000.

MCNEMAR, Q. "Note on the Sampling Error of the Differences Between Correlated Proportions of Percentages." Psychometrika 12 (1947): 153-157.

O’CONNOR, J. P., R. L. PRIEM, J. E. COOMBS, and K. M. GILLEY. "Do CEO Stock Options Prevent or Promote Fraudulent Financial Reporting?" Academy of Management Journal 49 (2006): 483-500.

PALMROSE, Z., V. J. RICHARDSON, and S. SCHOLZ. "Determinants of Market Reactions to Restatement Announcements." Journal of Accounting \& Economics 37 (2004): 59-89.

ROSENBAUM, P. R. Observational Studies, 2nd ed. Springer Series in Statistics, Berlin (2002).

ROSENBAUM, P. R., and D. B. RUBIN. "The Central Role of the Propensity Score in Observational Studies for Causal Effects.” Biometrika 70 (1983): 41-55.

ROY, A. D. "Some Thoughts on the Distribution of Earnings." Oxford Economic Papers 3 (1951): 135-146.

RUBIN, D. B. "Estimating Causal Effects of Treatments in Randomized and Nonrandomized Studies." Journal of Educational Psychology 66 (1974): 688-701.

RUBIN, D. B. "Assignment to a Treatment Group on the Basis of a Covariate." Journal of Educational Statistics 2 (1977): 1-26.

RUBIN, D. B. "Bayesian Inference for Causal Effects: The Role of Randomization.” Annals of Statistics 6 (1978): 34-58.

SMITH C., and R. WATTS. "The Investment Opportunity Set and Corporate Financing, Dividend, and Compensation Policies." Journal of Financial Economics 32 (1992): 263292. 
SEKHON, J. S. "Multivariate and Propensity Score Matching Software With Automated Balance Optimization: The Matching Package for R." Journal of Statistical Software (2008), forthcoming.

WEISBACH, M. S. "Outside Directors and CEO Turnover." Journal of Financial Economics 20 (1988): 431-460.

YERMACK, D. "Higher Market Valuation of Companies With a Small Board of Directors." Journal of Financial Economics 40 (1996): 185-211. 


\section{Appendix A. Background for an Observational Study}

The potential outcomes framework (Rubin, 1974, 1977; Holland, 1986; Heckman and Navarro-Lozano ,2004) is useful for illustrating the features of an observational study. Assume that, for each individual $i$, there is an indicator $D_{i}$ that equals one if the individual receives the treatment (e.g., high equity incentives) and equals zero otherwise. For each individual there is a potential outcome (e.g., accounting irregularity) if the individual receives the treatment, denoted $Y_{l}$, and another potential outcome (e.g., no accounting irregularity) if the individual does not receive the treatment, denoted $Y_{0}$. The potential outcomes for each individual are defined as $Y_{i}=$ $Y_{i}\left(D_{i}\right)$, and these are a function of both observable (denoted by $X$ ) and unobservable outcomespecific covariates (denoted by $\varepsilon_{0}$ and $\varepsilon_{1}$ ). ${ }^{34}$ In the case of additive separability, we can write these outcomes as follows.

$$
\begin{aligned}
& Y_{l}=\mu_{l}(X)+\varepsilon_{1} \\
& Y_{0}=\mu_{0}(X)+\varepsilon_{0} .
\end{aligned}
$$

The individual-level treatment effect, $\Delta=\left(Y_{I}-Y_{0}\right)$, represents the effect of the treatment on a particular individual. ${ }^{35}$ Although this quantity exists in theory, it cannot be observed because only one of the two potential outcomes is observed for any particular individual. The outcome that did not occur (e.g., $Y_{0}$ if the treatment was not received) is referred to as the "counterfactual" outcome, and its unobservability creates an identification problem that precludes the determination of the treatment effect for a specific individual.

\footnotetext{
${ }^{34}$ The unobservable components $\varepsilon_{0}$ and $\varepsilon_{1}$ are indexed separately to allow for the possibility that these factors differ according to whether treatment was received. If the incidence of treatment is related to unobservables $\varepsilon_{0}$ and $\varepsilon_{1}$, then there is an endogenous relationship known as selection on the unobservables (Heckman and Robb, 1985), which results in hidden bias. Below, we discuss how bounds can be established on the size of this relationship relative to the relationship between the outcome and the observable variables.

35 A treatment effect is often referred to as a "causal effect," which is defined as the difference between an observed outcome and its unobserved, counterfactual outcome.
} 
One way to address this identification problem is to group observations according to whether they received the treatment and estimate the difference between the average outcomes of the treatment and control groups (i.e., those that did and did not receive the treatment, respectively), which can identify the average treatment effect (ATE). One particularly important estimator of the average treatment effect is the average treatment effect on the treated (ATT), which is the effect of treatment for those individuals who actually receive treatment. ${ }^{36}$

$$
\begin{aligned}
A T T & =E[\Delta \mid X, D=1] \\
& =E\left[Y_{1}-Y_{0} \mid X, D=1\right] \\
& =E\left[Y_{1} \mid X, D=1\right]-E\left[Y_{0} \mid X, D=1\right] \\
& =E\left[Y_{1} \mid X, D=1\right]-E\left[Y_{0} \mid X, D=0\right] .
\end{aligned}
$$

The ATT estimator compares the average outcome for those individuals who received treatment $\left(Y_{I}\right)$ to the average outcome for those individuals who did not receive treatment (which serve as an estimate of the counterfactual outcome, $Y_{0}$ ).

In a matched-pair research design, each observation that received the treatment is paired with an observation that is similar along all other relevant observable dimensions (i.e., $X$ ) but that did not receive the treatment. Since each matched pair is similar in every observable respect except that one observation received the treatment while the other did not, any difference in the outcome can, in the absence of hidden bias, be attributed to the difference in treatment. The average effect of the treatment is calculated by combining equations (A1a) and (A1b) with equation (A2) as follows. ${ }^{37}$

\footnotetext{
${ }^{36}$ The identifying assumption required to estimate $A T T$ (and, implicitly, used by the matching method to estimate the $A T T$ ) derived by Heckman, et al. (1997) is $E\left[Y_{0} \mid X, D=1\right]=E\left[Y_{0} \mid X, D=0\right]=\mathrm{E}\left[\mathrm{Y}_{0} \mid \mathrm{X}\right]$. This requires that the expected outcome of those not receiving treatment conditional on the observable covariates $X$ is the same regardless of whether treatment was received.

${ }^{37}$ The second step is based on the assumption that $E\left[\varepsilon_{l} \mid X, D=1\right]=E\left[\varepsilon_{0} \mid X, D=0\right]=E[\varepsilon \mid X]$ or that the error is mean independent of the treatment. This assumption is referred to as "selection on observables" (Heckman and
} 


$$
\begin{aligned}
E\left[Y_{1}-Y_{0} \mid X, D\right] & =E\left[\mu_{1}(X)-\mu_{0}(X)+\varepsilon_{1}-\varepsilon_{0} \mid X, D\right] \\
& =E\left[\mu_{1}(X)+\varepsilon_{1} \mid X, D=1\right]-E\left[\mu_{0}(X)+\varepsilon_{0} \mid X, D=0\right] \\
& =E\left[\mu_{1}(X) \mid X, D=1\right]-E\left[\mu_{0}(X) \mid X, D=0\right] \\
& =E\left[\mu_{1}(X) \mid X, D=1\right]-E\left[\mu_{0}(X) \mid X, D=1\right] \\
& =E\left[\mu_{1}(X)-\mu_{0}(X) \mid X\right] .
\end{aligned}
$$

It is important to note that even if the functional forms of $\mu_{1}$ and $\mu_{0}$ are different, matching on $X$ will still produce an unbiased estimate of the average treatment effect.

An alternative way to develop an estimator of the average treatment effect is to recast equations (A1a) and (A1b) in a "switching regression” framework (e.g., Roy (1951), Goldfeld and Quandt (1973), and Rubin (1978)) to yield the following linear model:

$$
\begin{aligned}
Y & =Y_{0}+\left(Y_{1}-Y_{0}\right) D \\
& =\alpha_{0}+\beta_{0} X+\varepsilon_{0}+\left(\alpha_{1}+\beta_{1} X+\varepsilon_{1}-\left(\alpha_{0}+\beta_{0} X+\varepsilon_{0}\right)\right) D .
\end{aligned}
$$

If the treatment solely affects the level of the outcome so that there is a homogeneous treatment effect (i.e., $\beta_{0}=\beta_{1}$ and $\varepsilon_{0}=\varepsilon_{1}$ ), this equation simplifies to

$$
Y=\alpha_{0}+\beta X+\left(\alpha_{1}-\alpha_{0}\right) D+\varepsilon
$$

and the estimated coefficient on the treatment indicator, $D$, provides an estimate of the treatment effect (i.e., $\alpha_{1}-\alpha_{0}$ ). This approach assumes a linear relationship between the outcome and controls. It also assumes that the relationship between the outcome and every control variable is identical for the treatment and control samples. The implications of violating these assumptions are developed in Appendix B.

Robb, 1985) because it implies that there are no unobserved factors that affect selection into the treatment and control groups. As we discuss further below, one way to assess the importance of this assumption is to establish boundaries on the significance level of the results, to assess the degree to which selection on unobservable variables would be required to alter the conclusions of the study (Rosenbaum, 2002). 


\section{Appendix B}

\section{Comparison of Matching and Regression Approaches}

To compare the efficacy of propensity-score matching relative to regression methods (including partial matching with regression), we rely on Figure B1, which depicts three cases of the true underlying relationship between $Y$ (the outcome) and $X$ (the observed covariate or control variable). We assume that the probability density functions for $Y$ given $X$ are distributed normally with different means and possibly different variances. In the first case (Panel A), both the treatment and control observations exhibit an identical linear relationship between $X$ and $Y$. In the second case (Panel B), both the treatment and control observations exhibit a non-identical linear relationship between $X$ and $Y$. In particular, the degree to which treatment affects the outcome is linear in both the treatment and control samples, but the slopes differ across this partition. In the third (and perhaps most realistic) case (Panel C), both the treatment and control observations exhibit a non-identical, non-linear relationship between $X$ and $Y$. In this setting, the degree to which treatment affects the outcome may be non-linear for both the treatment and control groups, and the functional form of the relationship differs across this partition.

Perhaps because of perceived difficulty in identifying an appropriate match across multiple dimensions, researchers often use a partial match with regression-controls research design. In this design, researchers match observations along only a few dimensions (e.g., year, industry, and size) and then "control" for other dimensions by including additional variables in a regression analysis (e.g., structure of the board of directors). Inferences from this research design (or from a regression without matching), however, rely on potentially unrealistic, stringent assumptions about the underlying relationship between the outcome variable and the "control" variables. If these assumptions are not satisfied, inferences are likely to be confounded. Consider, for example, a setting in which two firms are matched on size and 
industry membership and for which there is an additional covariate (e.g., board size) that is expected to be related to the outcome of interest. If the researcher pools observations, includes a treatment indicator, $D$, and estimates a linear regression of this relationship, the estimation model resembles:

$$
Y_{i}=\alpha+\gamma D_{i}+\beta X_{i}+\varepsilon,
$$

where $X$ is a covariate that is not included in the matching procedure but is instead included as a "control." 38 For this estimation, it can be shown that the coefficient for $X$ at the point $X=$ $E\left(X_{O S}\right)$ reflects a weighted average of the slope coefficients that would be estimated within the treatment and control groups separately. ${ }^{39}$

In the case of an identical linear treatment effect illustrated in Panel A of Figure B1, the estimated coefficient on the treatment indicator will provide an unbiased estimate of the average treatment effect (i.e., $\left.E\left[Y_{1} \mid D=1, X\right]-\mathrm{E}\left[Y_{0} \mid D=0, X\right]\right)$. This occurs because the slope coefficients are identical for both the treatment and control groups and can be seen from the expression for $\gamma$, which is the estimate of the treatment effect in equation (B1). The covariate in the regression essentially adjusts the estimated treatment and control means to the mean value of the covariate in the overlapping support, $X_{O S}$ (although any value in the overlapping support will provide identical estimates in this case).

In the case of a non-identical linear treatment effect, illustrated in Panel B of Figure B1, the coefficient estimate of the treatment indicator from equation (B1) will yield a biased estimate of the treatment effect, $\gamma$. This biased estimate occurs because the estimated slope coefficient in

\footnotetext{
${ }^{38}$ For this example, we assume a linear functional form for expositional purposes only. The issues we discuss in this section generalize to any specific functional form estimation of a pooled, partial-match regression setting with additional controls.

${ }^{39}$ Specifically, $\beta=\rho \beta_{I}+(1-\rho) \beta_{0}$, where $\rho$ and $(1-\rho)$ is the fraction of the pooled sample that is from the treatment (control) group, respectively, and $\beta_{0}$ and $\beta_{1}$ represent the within-control and within-treatment sample slope coefficients, respectively. The average treatment effect is evaluated at point $E\left(X_{O S}\right)$, since it is the expected value within the region of overlapping support for $X$.
} 
equation (B1) is the weighted-average pooled estimate for both the treatment and control samples, and this pooled estimate is not equal to the actual slope for either of the samples, so the estimated counterfactual is incorrect. In the particular case illustrated in Panel B, the estimated treatment effect from equation (B1) will underestimate the true, average treatment effect. Conversely, the estimate of the control on the outcome will be overstated because a portion of the treatment effect will be misattributed to the control. ${ }^{40}$ A solution to this problem (similar to the test of parallel lines in traditional analysis of covariance) is to alter equation (B1) to incorporate a separate intercept and slope for each sample and estimate: ${ }^{41}$

$$
Y_{i}=\alpha+\gamma D_{i}+\beta X_{i}+\delta D_{i} \cdot X_{i}+\varepsilon_{i}
$$

If the researcher can correctly specify the functional form linking $X$ and $Y$ (e.g., linear over the entire range of $X$ ), the transformation from equation (B1) to equation (B2) will provide an unbiased estimate for the treatment effect.

Finally, the case of a non-identical, non-linear treatment effect is illustrated in Panel C of Figure B1. It can easily be seen that estimating a model similar to equation (B1) will almost never provide an unbiased estimate of the desired treatment effect. In the unlikely case that the underlying nonlinear structural model is known, the functions depicted in Panel $\mathrm{C}$ can be estimated and the treatment effect can be evaluated at any point, but not by using linear regression. Fortunately, the average treatment effect can be estimated with a matched pair research design, as shown in Appendix A.

\footnotetext{
40 The situation can also be reversed, depending on the relationship between the control covariate and the outcome in the treatment and control subsamples. It can easily be the case that the true average treatment effect is overstated because part of the effect of the control on the outcome is misattributed to the treatment. The key point is that the coefficient on the indicator variable in equation (A5) is not the correct estimate for the treatment effect.

${ }^{41}$ Although this is a simple estimation modification, none of the papers discussed in Table 1 examine whether the slopes on the covariates differ across the treatment and control groups.
} 
The discussion above shows that the addition of "control" variables in a regression framework may not adequately control for the effect of confounding variables on the outcome of interest. In particular, Panel A of Figure B1 illustrates the highly specialized case in which this approach will provide an unbiased estimate of the average treatment effect. However, this outcome requires a constant slope linking $X$ to $Y$ across groups. Panels B and $\mathrm{C}$ of Figure B1 illustrate how, in the more general case, modeling the relationship as linear results in a biased estimate of the treatment effect. In general, a matched research design (in which the match is performed along all relevant, observable dimensions) will provide a more robust estimate of the average treatment effect. The only case in which the regression approach can dominate the propensity-score matched design occurs when the structural model linking the outcome variable to the covariates is known and can be fully specified. However, knowledge of the underlying structural model is extremely unlikely, and misspecification of this structural model can result in additional sources of bias in the estimates of the treatment effect. 
Figure B1: Inferring Causal Effects Without Covariate Balance

Panel A.

Linear Relationship, parallel

Regression: $Y_{i}=\alpha+\gamma D i+\beta X i+\varepsilon$,

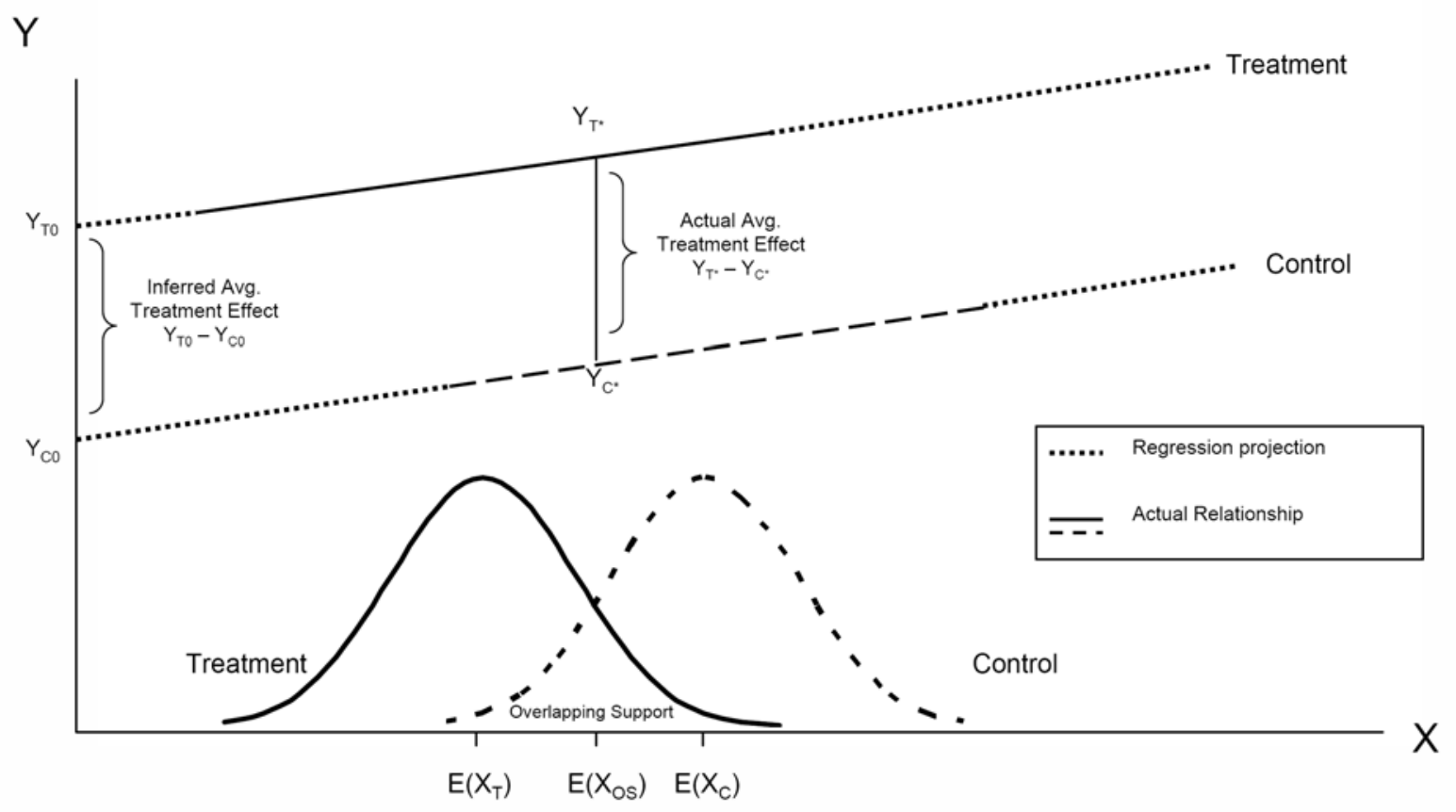




\section{Figure B1: Inferring Causal Effects Without Covariate Balance}

\section{Panel B.}

\section{Linear Relationship, non-parallel}

Regression: $Y i=\alpha+y D i+\beta X i+\varepsilon$,

Treatment

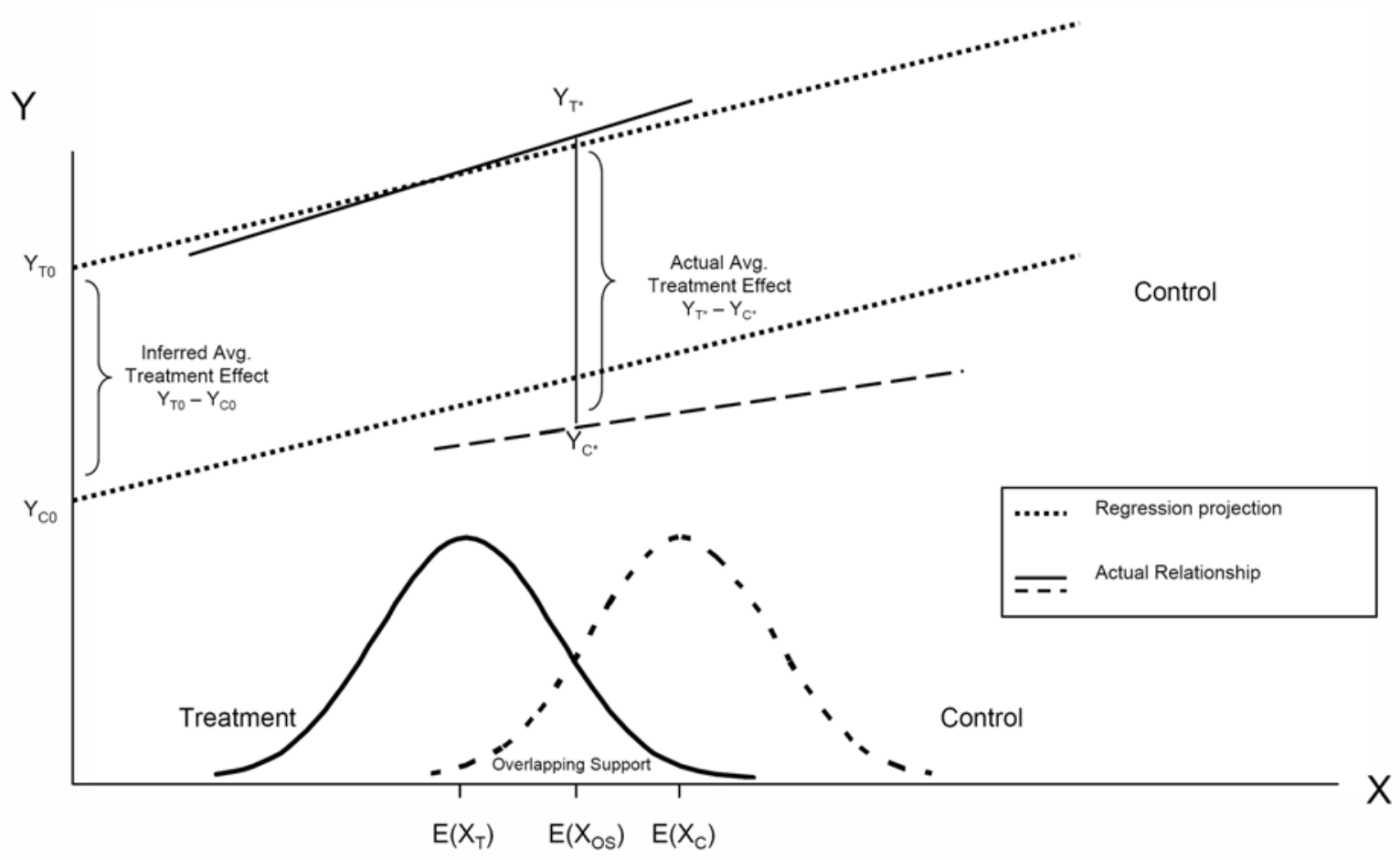




\section{Figure B1: Inferring Causal Effects Without Covariate Balance}

\section{Panel C.}

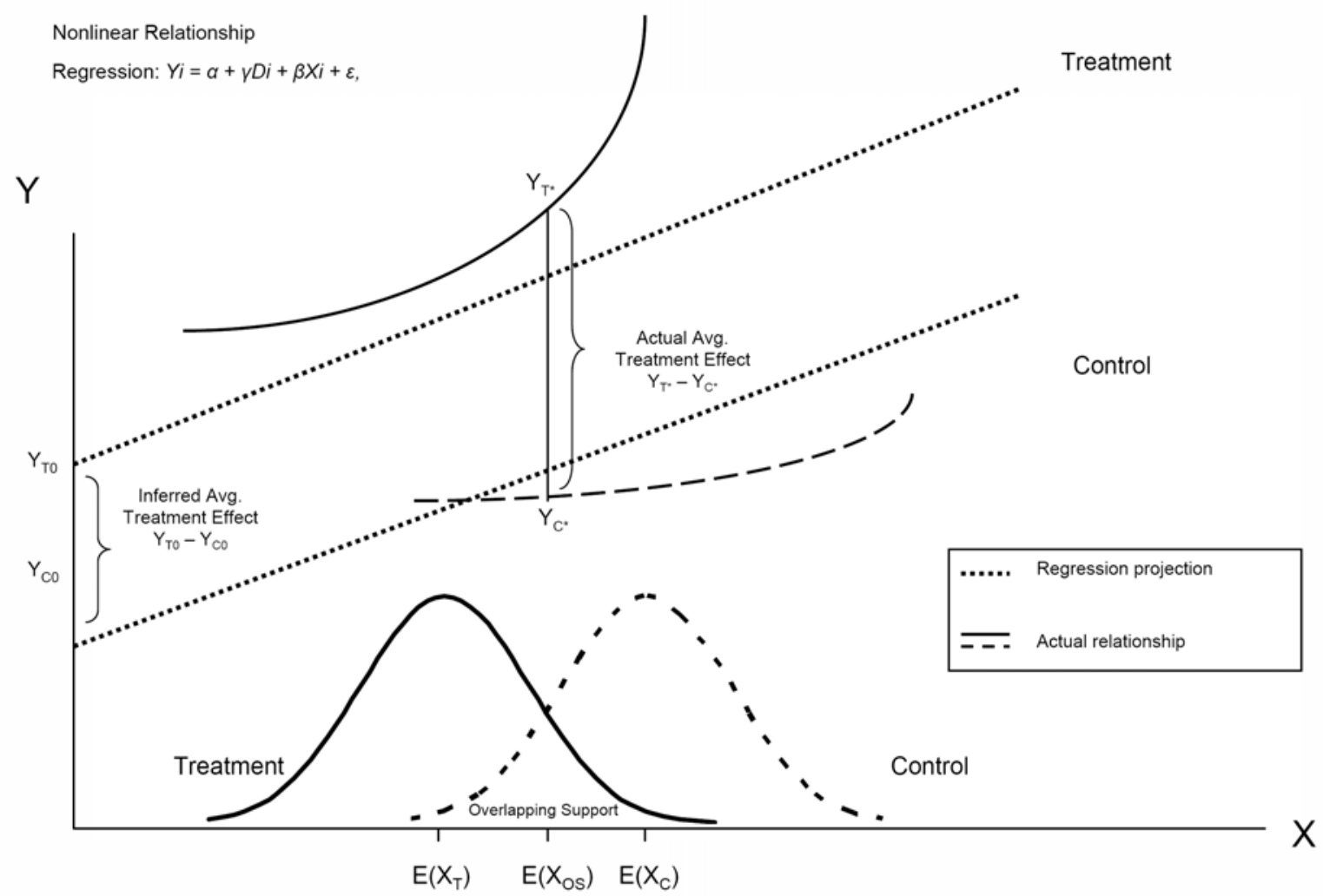

This figure depicts a nonlinear relationship between the dependent and independent variables (i.e., X and Y, respectively) for both the treatment and control samples. The average treatment effect is appropriately evaluated at the average of the overlapping support. Matching accomplishes this task by using only observations from the treatment and control samples in the region of overlapping support. Linear regression with a treatment indicator estimates a linear projection over the entire support of both the treatment and control distributions and assumes an identical slope, but different intercepts for the two samples. In this example, the average treatment effect estimated from linear regression will underestimate the average treatment effect. 


\section{Appendix C}

\section{Variable Definitions}

\begin{tabular}{|c|c|c|}
\hline Variable & Definition & Data Source \\
\hline EqIncQuint & $\begin{array}{l}\text { the quintile ranking of the CEO's portfolio delta for which quintiles } \\
\text { are computed annually from the cross-sectional distribution of } \\
\text { portfolio deltas. Portfolio delta is calculated as the change in the } \\
\text { risk-neutral dollar value of the CEO's equity portfolio for a } 1 \% \\
\text { change in the firm's stock price }\end{array}$ & Equilar \\
\hline Leverage & $\begin{array}{l}\text { the ratio of total debt to market value of assets computed as (data9 }+ \\
\text { data34)/((data199 } \cdot \text { data25) }+ \text { data9) }\end{array}$ & Compustat \\
\hline MarketCap & the market value of equity computed as (data199 $\cdot$ data25) & Compustat \\
\hline Idiosyncrisk & $\begin{array}{l}\text { the standard deviation of residuals from a firm-specific regression of } \\
\text { monthly returns on the monthly return to the CRSP value-weighted } \\
\text { portfolio index using the previous } 36 \text { months (and requiring at least } \\
12 \text { months) of observations (Core and Guay, 1999) }\end{array}$ & CRSP \\
\hline MkttoBook & $\begin{array}{l}\text { the market value of equity divided by the book value of equity } \\
\text { computed as }((\text { data199* data25)/data216) }\end{array}$ & Compustat \\
\hline Tenure & the CEO's tenure with the firm in years & Equilar \\
\hline OutsideChmn & $\begin{array}{l}\text { a dichotomous variable that equals one if the chairman of the Board } \\
\text { of Directors is an outsider and zero otherwise }\end{array}$ & Equilar \\
\hline OutsideLdDir & $\begin{array}{l}\text { a dichotomous variable that equals one if the firm has appointed a } \\
\text { lead independent director and zero otherwise }\end{array}$ & Equilar \\
\hline CEOApptdOutsDirs & $\begin{array}{l}\text { the fraction of outside directors appointed by the CEO; calculated as } \\
\text { the number of outside directors whose tenure is less than the CEO's } \\
\text { tenure, scaled by the total number of directors }\end{array}$ & Equilar \\
\hline StaggeredBd & $\begin{array}{l}\text { a dichotomous variable that equals one if the corporate directors } \\
\text { have staggered terms and zero otherwise }\end{array}$ & Equilar \\
\hline PctOldOutsDirs & $\begin{array}{l}\text { the number of outside directors who are at least } 69 \text { years old scaled } \\
\text { by the total number of directors }\end{array}$ & Equilar \\
\hline PctBusyOutsDirs & $\begin{array}{l}\text { the number of outside directors who serve simultaneously on at least } \\
\text { two boards scaled by the total number of directors }\end{array}$ & Equilar \\
\hline PctFoundingDirs & $\begin{array}{l}\text { the number of directors who are founders of the firm scaled by the } \\
\text { total number of directors }\end{array}$ & Equilar \\
\hline OutsideDirHolds & $\begin{array}{l}\text { the number of shares held by outside directors scaled by the total } \\
\text { number of shares outstanding }\end{array}$ & Equilar \\
\hline NumberDirs & the number of directors on the board & Equilar \\
\hline PctFinExpsAud & $\begin{array}{l}\text { the number of directors with financial expertise who serve on the } \\
\text { audit committee scaled by the total number of directors. Financial } \\
\text { experts are directors who have experience as CEO, CFO, financial } \\
\text { accountant, or auditor, or who have been licensed as a Certified } \\
\text { Public or Chartered Accountant. This variable is manually coded }\end{array}$ & Equilar \\
\hline
\end{tabular}




\section{from detailed biographical data}

DirCompMix the ratio of total dollar equity compensation to total equity plus cash Equilar compensation for non-executive directors

NumberInstOwns the number of institutional owners of the firm's shares

CDA/Spectrum

NumBlockhldrs

the number of institutional owners that own at least $5 \%$ of the firm's

$\mathrm{CDA} /$ Spectrum outstanding shares

Activists

the number of institutional owners denoted as activists. Activist shareholders are identified as CDA/Spectrum manager numbers $12000,12100,12120,18740,38330,81590,49050,54360,57500$, $58650,63600,63850,63895,66550,66610,66635,82895,83360$, 90803, and 93405 (Cremers and Nair, 2005; Larcker, Richardson, and Tuna, 2007). 


\section{Figure 1}

\section{Accounting Irregularities: Frequency Distributions}

Frequency of observed Accounting Irregularities for each equity-incentive quintile (Contemporaneous $n=13,706$; One Year Ahead $n=10,773$ )
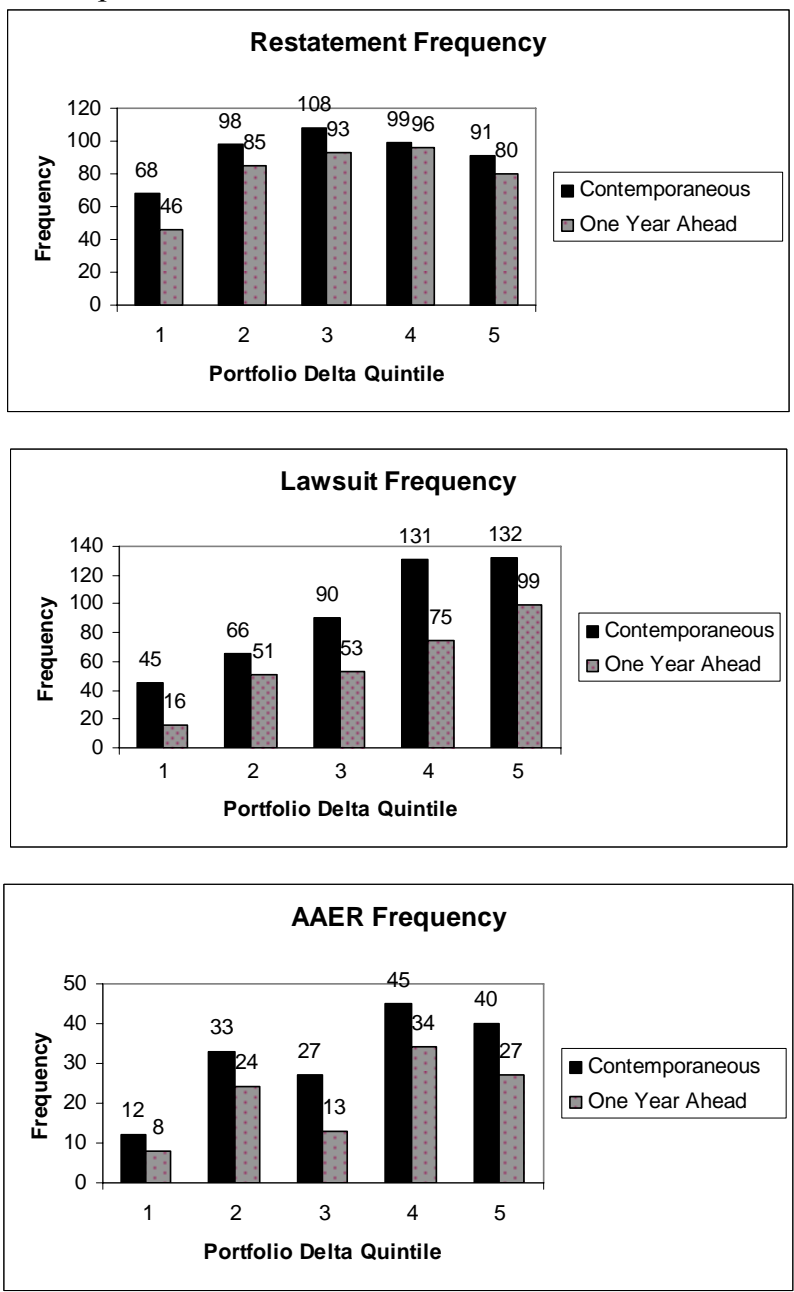

Accounting Irregularity frequency is presented for each quintile of CEO equity incentives. CEO equity incentives is measured as the portfolio delta (PortDelta), which is the change in the risk-neutral dollar value of the CEO's equity portfolio for a 1\% change in the firm's stock price (Core and Guay, 1999). To compute PortDelta, the value of stock and restricted stock is assumed to change dollar-for-dollar with changes in the price of the underlying stock. The value of stock options is assumed to change according to the option's delta, which is the derivative of its BlackScholes value with respect to the price of the underlying stock (See Core and Guay, 2002). Black-Scholes parameters are computed using methods similar to Core and Guay (2002). Specifically, annualized volatility is calculated using continuously compounded monthly returns over the prior 36 months (with a minimum of 12 months of returns). The risk-free rate is calculated using an interpolated interest rate on a Treasury note with the same maturity (to the closest month) as the remaining life of the option multiplied by 0.7 to account for the prevalence of early-exercise. Dividend Yield is calculated as the dividends paid over the past 12 months scaled by the stock price at the beginning of the month. Contemporaneous Irregularities are those that occur in the same fiscal year of CEO equity incentives measurement. One Year Ahead Irregularities are those that occur in the fiscal year that follows $\mathrm{CEO}$ equity-incentive measurement. 
Table 1

Summary of Prior Literature

\begin{tabular}{|c|c|c|c|c|c|c|}
\hline Study & $\begin{array}{l}\text { Primary Equity } \\
\text { Incentives Proxy }\end{array}$ & $\begin{array}{l}\text { Accounting } \\
\text { Irregularities Proxy }\end{array}$ & $\begin{array}{l}\text { Unit of } \\
\text { Analysis }\end{array}$ & Research Design & Sample & $\begin{array}{l}\text { Observed } \\
\text { Association }\end{array}$ \\
\hline $\begin{array}{l}\text { Baber, Kang, } \\
\text { Liang (2007) }\end{array}$ & $\begin{array}{l}\text { Compensation Mix, } \\
\text { Exercisable Options } \\
\text { scaled by Shares } \\
\text { Outstanding }\end{array}$ & Restatements & $\mathrm{CEO}$ & $\begin{array}{l}\text { Matched pair (year, } \\
\text { industry, exchange, assets) } \\
\text { logistic regression }\end{array}$ & $\begin{array}{l}193 \text { firm-years } \\
\text { plus matches, } \\
1997-2002\end{array}$ & None \\
\hline $\begin{array}{l}\text { Harris and } \\
\text { Bromiley (2007) }\end{array}$ & $\begin{array}{l}\text { Option and Bonus } \\
\text { Value scaled by } \\
\text { Total Compensation } \\
\text { Value }\end{array}$ & Restatements & $\mathrm{CEO}$ & $\begin{array}{l}\text { Matched pair (year, } \\
\text { industry, sales) conditional } \\
\text { logistic regression }\end{array}$ & $\begin{array}{l}434 \text { firm-years } \\
\text { plus matches, } \\
1997-2002\end{array}$ & $\begin{array}{l}\text { Positive for Option } \\
\text { Value scaled by } \\
\text { Total Compensation } \\
\text { Value }\end{array}$ \\
\hline $\begin{array}{l}\text { Larcker, } \\
\text { Richardson, Tuna } \\
(2007)\end{array}$ & Compensation Mix & $\begin{array}{l}\text { Abnormal Accruals, } \\
\text { Restatements }\end{array}$ & $\mathrm{CEO}$ & $\begin{array}{l}\text { OLS regression, Pooled } \\
\text { logistic regression }\end{array}$ & $\begin{array}{l}\text { 1,484 firm-years, } \\
118 \text { firm-years } \\
\text { plus all other } \\
\text { firm-year } \\
\text { observations, } \\
2002-2003\end{array}$ & Positive, None \\
\hline $\begin{array}{l}\text { Efendi, } \\
\text { Srivastava, } \\
\text { Swanson (2007) }\end{array}$ & $\begin{array}{l}\text { Component Value, } \\
\text { Option Intrinsic } \\
\text { Value, Option Delta }\end{array}$ & $\begin{array}{l}\text { Restatements, Severe } \\
\text { Restatements }\end{array}$ & $\mathrm{CEO}$ & $\begin{array}{l}\text { Matched pair (year, } \\
\text { industry, assets) logistic } \\
\text { regression, ordered logistic } \\
\text { regression }\end{array}$ & $\begin{array}{l}95 \text { firm-years plus } \\
\text { matches, 2001- } \\
2002\end{array}$ & $\begin{array}{l}\text { Positive for option } \\
\text { intrinsic value and } \\
\text { option delta }\end{array}$ \\
\hline $\begin{array}{l}\text { Erickson, } \\
\text { Hanlon, Maydew } \\
(2006)\end{array}$ & Portfolio Delta & AAERs & Top 5 execs & $\begin{array}{l}\text { Matched firms (year, } \\
\text { industry, assets) logistic } \\
\text { regression }\end{array}$ & $\begin{array}{l}50 \text { firm-years plus } \\
\text { matches, 1996- } \\
2003\end{array}$ & None \\
\hline $\begin{array}{l}\text { Johnson, Ryan, } \\
\text { Tian (2009) }\end{array}$ & $\begin{array}{l}\text { Portfolio Delta and } \\
\text { Component Deltas }\end{array}$ & AAERs & $\begin{array}{l}\text { Top } 5 \text { execs } \\
\text { and } \mathrm{CEO} \\
\text { only }\end{array}$ & $\begin{array}{l}\text { Matched pair (year, } \\
\text { industry, revenues) } \\
\text { conditional logistic } \\
\text { regression }\end{array}$ & $\begin{array}{l}53 \text { firm-years plus } \\
\text { matches, 1992- } \\
2001\end{array}$ & $\begin{array}{l}\text { Positive only for } \\
\text { incentives related to } \\
\text { unrestricted stock }\end{array}$ \\
\hline
\end{tabular}


Table 1 (continued)

Summary of Prior Literature

\begin{tabular}{|c|c|c|c|c|c|c|}
\hline Study & $\begin{array}{l}\text { Primary Equity } \\
\text { Incentives Proxy }\end{array}$ & $\begin{array}{l}\text { Accounting } \\
\text { Irregularities Proxy }\end{array}$ & $\begin{array}{l}\text { Unit of } \\
\text { Analysis }\end{array}$ & Research Design & Sample & $\begin{array}{l}\text { Observed } \\
\text { Association }\end{array}$ \\
\hline $\begin{array}{l}\text { Burns, Kedia } \\
(2006)\end{array}$ & $\begin{array}{l}\text { Portfolio Delta and } \\
\text { Component Deltas }\end{array}$ & $\begin{array}{l}\text { Restatements, } \\
\text { Restatement } \\
\text { Magnitude }\end{array}$ & CEO & $\begin{array}{l}\text { Pooled logistic regression, } \\
\text { Pooled OLS regression }\end{array}$ & $\begin{array}{l}266 \text { firm-years } \\
\text { plus all other } \\
\text { ExecuComp } \\
\text { firm-years, } \\
1995-2002\end{array}$ & $\begin{array}{l}\text { Positive only for } \\
\text { incentives related } \\
\text { to stock options }\end{array}$ \\
\hline $\begin{array}{l}\text { Bergstresser, } \\
\text { Philippon (2006) }\end{array}$ & $\begin{array}{l}\text { Incentive Ratio } \\
\text { (Portfolio Delta } \\
\text { scaled by } \\
\text { compensation) }\end{array}$ & $\begin{array}{l}\text { Discretionary } \\
\text { Accruals }\end{array}$ & CEO & OLS regression & $\begin{array}{l}4,761 \text { firm- } \\
\text { years, 1994- } \\
2000\end{array}$ & Positive \\
\hline $\begin{array}{l}\text { O'Connor, Priem, } \\
\text { Coombs, Gilley } \\
(2006)\end{array}$ & $\begin{array}{l}\text { Black Scholes } \\
\text { Option Value }\end{array}$ & Restatements & CEO & $\begin{array}{l}\text { Matched pair (year, } \\
\text { industry, sales, income, } \\
\text { option vesting schedules) }\end{array}$ & $\begin{array}{l}65 \text { firm-years } \\
\text { plus matches, } \\
2000-2004\end{array}$ & $\begin{array}{l}\text { Positive if (1) CEO } \\
\text { is board chair and } \\
\text { other board } \\
\text { members do not } \\
\text { receive options, or } \\
\text { (2) CEO is not } \\
\text { board chair and } \\
\text { other board } \\
\text { members receive } \\
\text { options }\end{array}$ \\
\hline $\begin{array}{l}\text { Cheng, Warfield } \\
(2005)\end{array}$ & $\begin{array}{l}\text { Component } \\
\text { Holdings scaled by } \\
\text { shares outstanding }\end{array}$ & $\begin{array}{l}\text { Meet / Just Beat } \\
\text { Expectations, } \\
\text { Abnormal Accruals }\end{array}$ & CEO & $\begin{array}{l}\text { Pooled Logistic regression, } \\
\text { Pooled OLS }\end{array}$ & $\begin{array}{l}\text { 4,301 firm- } \\
\text { years, } 6,307 \\
\text { firm-years, } \\
1993-2000\end{array}$ & $\begin{array}{l}\text { Positive only for } \\
\text { unexercisable } \\
\text { options and stock } \\
\text { holdings }\end{array}$ \\
\hline
\end{tabular}




\section{Table 2}

\section{Descriptive Statistics for Accounting Irregularities, CEO Equity Incentives, and Firm Characteristics}

\begin{tabular}{lrrr}
\multicolumn{5}{l}{ Panel A. Accounting Irregularities $(\boldsymbol{n}=\mathbf{1 3}, \mathbf{7 0 6})$} & \\
\hline \hline Variable & Period & Number of Firms & Percentage \\
\hline Manipulation Restatement & Pooled & 464 & $3.4 \%$ \\
& 2001 & 17 & $0.1 \%$ \\
& 2002 & 69 & $0.5 \%$ \\
2003 & 96 & $0.7 \%$ \\
& 2004 & 203 & $1.5 \%$ \\
Accounting Lawsuit & 2005 & 79 & $0.6 \%$ \\
& Pooled & 464 & $3.4 \%$ \\
& 2001 & 122 & $0.9 \%$ \\
& 2002 & 98 & $0.7 \%$ \\
AAER & 2003 & 118 & $0.9 \%$ \\
& 2004 & 83 & $0.6 \%$ \\
& 2005 & 43 & $0.3 \%$ \\
& Pooled & 157 & $1.2 \%$ \\
& 2001 & 50 & $0.4 \%$ \\
& 2002 & 48 & $0.4 \%$ \\
& 2003 & 35 & $0.3 \%$ \\
& 2004 & 18 & $0.1 \%$ \\
& 2005 & 6 & $0.0 \%$ \\
\hline
\end{tabular}

Restatement data are obtained from Glass-Lewis \& Co., which comprehensively collects restatement information from SEC filings, press releases, and other public data. We identify accounting restatements between 2001 and 2005 that relate to perceived reporting manipulation classified as accounting fraud, an SEC investigation, a securities class action suit, improper reserve allowances, improper revenue recognition, or improper expense recognition. We code a restatement incident as the first fiscal year in which improper accounting occurred that subsequently required restatement.

Accounting lawsuits are obtained from a database provided by Woodruff-Sawyer and Co. that records class action lawsuit periods between 2001 and 2005. These lawsuits allege earnings estimate improprieties, financial misrepresentation, failure to adhere to GAAP, or restatement of earnings. We code a lawsuit incident as the first fiscal year in which the firm is named in a lawsuit damage period.

SEC Accounting and Auditing Enforcement Releases (AAERs) are identified from the comprehensive AAER listing provided on the SEC website for allegation periods between 2001 and 2005. These allegations cite earnings-estimate improprieties, financial misrepresentation, or failure to adhere to GAAP. We code an AAER incident as the first fiscal year in which the SEC alleges accounting manipulation occurred, as detailed in the Enforcement Release. 
Table 2 (continued)

Panel B. CEO Equity Incentives $(\mathbf{n}=10,773)$

\begin{tabular}{|c|c|c|c|c|c|c|c|c|c|c|c|}
\hline \multirow[t]{2}{*}{ Variable } & \multirow[t]{2}{*}{ Period } & \multicolumn{2}{|c|}{ EqIncQuint = 1} & \multicolumn{2}{|c|}{ EqIncQuint = 2} & \multicolumn{2}{|c|}{ EqIncQuint $=3$} & \multicolumn{2}{|c|}{ EqIncQuint = 4} & \multicolumn{2}{|c|}{ EqIncQuint = 5} \\
\hline & & Mean & Median & Mean & Median & Mean & Median & Mean & Median & Mean & Median \\
\hline \multirow[t]{6}{*}{ PortDelta } & Pooled & 24,980 & 24,357 & 88,124 & 84,941 & 210,928 & 204,436 & 519,365 & 489,012 & $4,819,973$ & $1,822,611$ \\
\hline & 2001 & 25,999 & 27,159 & 91,085 & 87,636 & 224,167 & 222,667 & 537,664 & 501,469 & $5,117,285$ & $2,114,765$ \\
\hline & 2002 & 17,086 & 16,875 & 62,607 & 60,660 & 153,596 & 149,491 & 400,245 & 379,358 & $4,274,464$ & $1,412,645$ \\
\hline & 2003 & 25,841 & 25,213 & 94,731 & 91,931 & 227,433 & 224,623 & 549,970 & 518,465 & $4,829,008$ & $1,863,581$ \\
\hline & 2004 & 28,628 & 27,830 & 99,706 & 97,226 & 230,843 & 223,186 & 572,769 & 548,654 & $4,994,529$ & $1,963,088$ \\
\hline & 2005 & 26,072 & 26,110 & 91,802 & 89,460 & 218,183 & 216,843 & 536,657 & 498,068 & $4,930,282$ & $1,879,171$ \\
\hline
\end{tabular}

CEO equity incentives are measured as the portfolio delta (PortDelta), which is the change in the risk-neutral dollar value of the CEO's equity portfolio for a $1 \%$ change in the firm's stock price (Core and Guay, 1999). To compute PortDelta, the value of stock and restricted stock is assumed to change dollar-for-dollar with changes in the price of the underlying stock. The value of stock options is assumed to change according to the option's delta, which is the derivative of its Black-Scholes value with respect to the price of the underlying stock (See Core and Guay, 2002). Black-Scholes parameters are computed using methods similar to Core and Guay (2002). Specifically, annualized volatility is calculated using continuously compounded monthly returns over the prior 36 months (with a minimum of 12 months of returns). The risk-free rate is calculated using an interpolated interest rate on a Treasury note with the same maturity (to the closest month) as the remaining life of the option multiplied by 0.7 to account for the prevalence of early exercise. Dividend Yield is calculated as the dividends paid over the past 12 months scaled by the stock price at the beginning of the month. 
Table 2 (continued)

Panel C. Firm Characteristics ( $\mathrm{n}=10,773)$

\begin{tabular}{lrrr}
\hline \hline Variable & Mean & Median & Std. Dev. \\
\hline Leverage & 0.204 & 0.144 & 0.231 \\
MarketCap & 3,775 & 551 & 16,791 \\
Idiosyncrisk & 0.152 & 0.130 & 0.088 \\
MkttoBook & 2.865 & 2.120 & 2.853 \\
Tenure & 6.862 & 4.800 & 7.235 \\
OutsideChmn & 0.132 & 0.000 & 0.339 \\
OutsideLdDir & 0.194 & 0.000 & 0.395 \\
CEOApptdOutsDirs & 0.700 & 0.800 & 0.329 \\
StaggeredBd & 0.580 & 1.000 & 0.494 \\
PctOldOutsDirs & 0.143 & 0.125 & 0.142 \\
PctBusyOutsDirs & 0.250 & 0.222 & 0.209 \\
PctFoundingDirs & 0.034 & 0.000 & 0.075 \\
OutsideDirHolds & 0.013 & 0.003 & 0.033 \\
NumberDirs & 8.600 & 8.000 & 2.633 \\
PctFinExpsAud & 0.674 & 0.667 & 0.244 \\
DirCompMix & 0.495 & 0.531 & 0.319 \\
NumInstOwns & 133 & 89 & 151 \\
NumBlockhldrs & 1.886 & 2.000 & 1.530 \\
Activists & 0.013 & 0.000 & 0.115 \\
\hline
\end{tabular}

Leverage is the ratio of total debt to market value of assets computed from Compustat as (data9 + data34)/((data199* data25) + data9). MarketCap is the market value of equity computed from Compustat as (data199* data25).

Idiosyncrisk is the standard deviation of residuals from a firm-specific regression of monthly returns on the monthly return to the CRSP value-weighted portfolio index (Core and Guay, 1999). At least 12 and no more than 36 monthly return observations are required for estimation. MkttoBook is the market value of equity divided by the book value of equity computed from Compustat as ((data199* data25)/data216). Tenure is the CEO's tenure with the firm in years, as provided by Equilar. OutsideChmn is a dichotomous variable that equals one if the board chairman is delineated as an outsider by Equilar and is zero otherwise. OutsideLdDir is a dichotomous variable that equals one if the lead independent director is delineated as an outsider by Equilar and is zero otherwise. CEOApptdOutsDirs is the number of outside directors whose tenure is less than the CEO's tenure, scaled by the total number of directors. StaggeredBd is a dichotomous variable that equals one if Equilar delineates the board service terms as staggered and is zero otherwise. PctOldOutsDirs is the ratio of outside directors who are at least 69 years old to total directors. PctBusyOutsDirs is the ratio of outside directors who serve simultaneously on at least two boards to total directors. PctFoundingDirs is the ratio of directors who are founding firm members to total directors. OutsideDirHolds is the sum of shares held by outside directors to total shares outstanding. NumberDirs is the number of directors on the board. PctFinExpsAud is the ratio of directors with financial expertise who serve on the audit committee to total directors. Directors are classified as financial experts if they have experience as CEO, CFO, financial accountant, or auditor, or if they have been licensed as a Certified Public or Chartered Accountant. DirCompMix is the ratio of total dollar equity compensation to total equity plus cash compensation for non-executive directors. NumberInstOwns is the number of institutional owners delineated in the CDA/Spectrum database. NumBlockhldrs is the number of institutional owners that own at least $5 \%$ of outstanding shares. Activists is the number of institutional owners denoted as activists by Cremers and Nair (2005) and Larcker, Richardson, and Tuna (2007). 
Table 3

Propensity-Score Estimation Using Conditional Ordered Logistic Regression

\begin{tabular}{lcrrrc}
\hline $\begin{array}{l}\text { Dependent Variable } \\
\text { EqIncQuint }\end{array}$ & Pred. & Avg. Coeff. & $\begin{array}{c}\text { Aggr. z- } \\
\text { Statistic }\end{array}$ & $\begin{array}{c}\text { Yrs. With } \\
\text { Pos. Coeff. }\end{array}$ & $\begin{array}{c}\text { Yrs. With } \\
\text { Neg. Coeff. }\end{array}$ \\
\hline Leverage & - & -0.398 & -3.938 & 0 & 4 \\
Log(MarketCap) & + & 1.524 & 41.320 & 4 & 0 \\
Log(Idiosyncrisk) & + & 0.111 & 2.438 & 4 & 0 \\
MkttoBook & + & 0.033 & 4.083 & 4 & 0 \\
Log(1+Tenure) & + & 0.734 & 32.190 & 4 & 0 \\
OutsideChmn & $?$ & -0.699 & -11.565 & 0 & 4 \\
OutsideLdDir & $?$ & -0.302 & -3.861 & 0 & 4 \\
CEOApptdOutsDirs & $?$ & 1.027 & 15.844 & 4 & 0 \\
StaggeredBd & $?$ & -0.031 & -0.824 & 2 & 2 \\
PctOldOutsDirs & $?$ & 0.085 & 0.674 & 2 & 2 \\
PctBusyOutsDirs & $?$ & -0.002 & 0.162 & 2 & 2 \\
PctFoundingDirs & $?$ & 3.015 & 10.837 & 4 & 0 \\
OutsideDirHolds & $?$ & 3.912 & 6.384 & 4 & 0 \\
Log(1+NumberDirs) & $?$ & -1.272 & -13.427 & 0 & 4 \\
PctFinExpsAud & $?$ & -0.006 & -0.136 & 2 & 2 \\
DirCompMix & $?$ & 0.298 & 4.522 & 4 & 0 \\
Log(1+NumInstOwns) & $?$ & -0.344 & -6.737 & 0 & 4 \\
Log(1+NumBlockhldrs) & $?$ & 0.195 & 5.432 & 4 & 0 \\
Log(1+Activists) & $?$ & -0.673 & -2.903 & 0 & 4 \\
Intercept EqIncQuint $1 \rightarrow 2$ & + & 4.524 & 21.288 & 4 & 0 \\
Intercept EqIncQuint $2 \rightarrow 3$ & + & 6.334 & 29.194 & 4 & 0 \\
Intercept EqIncQuint $3 \rightarrow 4$ & + & 7.882 & 35.516 & 4 & 0 \\
Intercept EqIncQuint $4 \rightarrow 5$ & + & 9.672 & 42.373 & 4 & \\
CEO-firm-year obs. & & 10,773 & & & \\
Adj. Pseudo-R ${ }^{2}$ & +0.273 & & & \\
\hline & + & & & & \\
\hline
\end{tabular}

EqIncQuint is a dichotomous variable that equals one if the CEO's portfolio delta falls within the $k$ th quintile of the crosssectional distribution of CEO deltas and equals zero otherwise. The portfolio delta is the change in dollar value of the CEO's equity portfolio for a $1 \%$ change in the firm's underlying stock price. Leverage is the ratio of total debt to market value of assets computed from Compustat as (data9 + data34)/((data199* data25) + data9). MarketCap is the market value of equity computed from Compustat as (data199* data25). Idiosyncrisk is the standard deviation of residuals from a firm-specific regression of monthly returns on the monthly return to the CRSP value-weighted portfolio index (Core and Guay, 1999). At least 12 and no more than 36 monthly return observations are required for estimation. MkttoBook is the market value of equity divided by the book value of equity computed from Compustat as ((data199* data25)/data216). Tenure is the CEO's tenure with the firm in years, as provided by Equilar. OutsideChmn is a dichotomous variable that equals one if the board chairman is delineated as an outsider by Equilar and is zero otherwise. OutsideLdDir is a dichotomous variable that equals one if the lead independent director is delineated as an outsider by Equilar and is zero otherwise. CEOApptdOutsDirs is the number of outside directors whose tenure is less than the CEO's tenure, scaled by the total number of directors. StaggeredBd is a dichotomous variable that equals one if Equilar delineates the board service terms as staggered and is zero otherwise. PctOldOutsDirs is the ratio of outside directors who are at least 69 years old to total directors. PctBusyOutsDirs is the ratio of outside directors who serve simultaneously on at least two boards to total directors. PctFoundingDirs is the ratio of directors who are founding firm members to total directors. OutsideDirHolds is the sum of shares held by outside directors to total shares outstanding. NumberDirs is the number of directors on the board. PctFinExpsAud is the ratio of directors with financial expertise who serve on the audit committee to total directors. Directors are classified as financial experts if they have experience as CEO, CFO, financial accountant, or auditor, or if they have been licensed as a Certified Public or 
Chartered Accountant. DirCompMix is the ratio of total dollar equity compensation to total equity plus cash compensation for non-executive directors. NumberInstOwns is the number of institutional owners delineated in the CDA/Spectrum database. NumBlockhldrs is the number of institutional owners that own at least $5 \%$ of outstanding shares. Activists is the number of institutional owners denoted as activists by Cremers and Nair (2005) and Larcker, Richardson, and Tuna (2007).

The first column reports the average coefficient estimate across year-specific estimation from 2001 through 2005 . The second column reports an aggregate $z$-statistic, which is calculated as the sum of the individual annual $z$-statistics divided by the square root of the number of years over which equation (2) is estimated. This aggregated $z$-statistic assumes that each annual estimation is independent of the other estimations. The final two columns report the number of years for which the year-specific coefficient is positive and negative, respectively. Adj. Pseudo $R^{2}$ is the average McFadden's adjusted pseudo $\mathrm{R}^{2}$. 


\section{Table 4}

\section{Matched-Pair Frequencies for Equity-Incentive Quintiles}

Frequencies of the dosage differences between the matched pairs

\begin{tabular}{ccccccc}
\hline $\begin{array}{c}\text { Control } \\
\text { Equity } \\
\text { Incentive } \\
\text { Quintile }\end{array}$ & $\mathbf{5}$ & Treatment Equity Incentive Quintile \\
& $\mathbf{1}$ & $\mathbf{2}$ & $\mathbf{3}$ & $\mathbf{4}$ & $\mathbf{5}$ & Total \\
\hline $\mathbf{1}$ & 0 & 670 & 188 & 25 & 71 & 954 \\
$\mathbf{2}$ & & 0 & 821 & 442 & 130 & 1,393 \\
$\mathbf{3}$ & & & 0 & 786 & 404 & 1,190 \\
$\mathbf{4}$ & & & & 0 & 1,022 & 1,022 \\
$\mathbf{5}$ & & & & & 0 & 0 \\
Total & 0 & 670 & 1,009 & 1,253 & 1,627 & 4,559 \\
\hline & & & & & & \\
\hline
\end{tabular}

Matched pairs are formed using the following distance metric:
$\Delta_{i, j}=\frac{\left(\text { PScore }_{i}-\text { PScore }_{j}\right)^{2}}{\left(\delta_{i}-\delta_{j}\right)^{2}}$
if $\delta_{i} \neq \delta_{j}$
$\Delta_{i, j}=$
if $\delta_{i}=\delta_{j}$,

PScore is the propensity score computed from equation (1), $\delta$ is each observation's equity incentive treatment quintile, and $i, j$ denote individual observations.

Matched pairs are identified through a nonbipartite algorithm to identify, across all possible permutations, the minimum sum of pairwise distances, $\sum \Delta_{i, j}$ for $i \neq j$, where each observation is paired with another and observations can be used only once for matching.

Higher equity-incentive observations are labeled as treatment, and lower equity-incentive observations are labeled as control. 


\section{Table 5}

\section{Covariate Balance Between the Matched Pairs}

Test statistics of covariate distributions for the treatment (high CEO equity incentives) and the control (low CEO equity incentives) groups ( $\mathrm{n}=4,559$ matched pairs)

\begin{tabular}{lcccccc}
\hline \hline & $\begin{array}{c}\text { Mean } \\
\text { Treatment }\end{array}$ & $\begin{array}{c}\text { Mean } \\
\text { Control }\end{array}$ & $\begin{array}{c}\text { Median } \\
\text { Treatment }\end{array}$ & $\begin{array}{c}\text { Median } \\
\text { Control }\end{array}$ & $\begin{array}{c}\boldsymbol{t} \text {-Test } \\
\text { Difference } \\
\boldsymbol{p} \text {-Value }\end{array}$ & $\begin{array}{c}\text { KS Bootstrap } \\
\text { Difference } \\
\boldsymbol{p} \text {-Value }\end{array}$ \\
\hline Leverage & 0.205 & 0.200 & 0.149 & 0.152 & 0.281 & 0.407 \\
Log(MarketCap) & 6.322 & 6.297 & 6.234 & 6.210 & 0.417 & 0.179 \\
Log(Idiosyncrisk) & -2.045 & -2.018 & -2.059 & -2.024 & 0.017 & 0.000 \\
MkttoBook & 2.785 & 2.770 & 2.113 & 2.028 & 0.794 & 0.002 \\
Log(1+Tenure) & 1.640 & 1.625 & 1.740 & 1.705 & 0.445 & 0.000 \\
OutsideChmn & 0.122 & 0.121 & 0.000 & 0.000 & 0.898 & 0.910 \\
OutsideLdDir & 0.157 & 0.160 & 0.000 & 0.000 & 0.667 & 0.687 \\
CEOApptdOutsDirs & 0.703 & 0.707 & 0.800 & 0.800 & 0.556 & 0.313 \\
StaggeredBd & 0.597 & 0.594 & 1.000 & 1.000 & 0.749 & 0.747 \\
PctOldOutsDirs & 0.152 & 0.152 & 0.125 & 0.133 & 0.945 & 0.252 \\
PctBusyOutsDirs & 0.239 & 0.242 & 0.200 & 0.200 & 0.450 & 0.153 \\
PctFoundingDirs & 0.036 & 0.035 & 0.000 & 0.000 & 0.436 & 0.000 \\
OutsideDirHolds & 0.014 & 0.014 & 0.003 & 0.003 & 0.854 & 0.001 \\
Log(NumberDirs) & 2.222 & 2.222 & 2.197 & 2.197 & 0.927 & 0.758 \\
PctFinExpsAud & 0.745 & 0.750 & 1.000 & 1.000 & 0.531 & 0.540 \\
DirCompMix & 0.495 & 0.507 & 0.549 & 0.537 & 0.075 & 0.000 \\
Log(NumInstOwns) & 4.359 & 4.368 & 4.466 & 4.466 & 0.640 & 0.822 \\
Log(NumBlockhldrs) & 0.895 & 0.917 & 1.099 & 1.099 & 0.067 & 0.009 \\
Log(Activists) & 0.009 & 0.010 & 0.000 & 0.000 & 0.647 & 0.697 \\
\hline
\end{tabular}

Leverage is the ratio of total debt to market value of assets computed from Compustat as $($ data9 + data34)/(data199* data25) + data9). MarketCap is the market value of equity computed from Compustat as (data199* data25). Idiosyncrisk is the standard deviation of residuals from a firm-specific regression of monthly returns on the monthly return to the CRSP value-weighted portfolio index (Core and Guay, 1999). At least 12 and no more than 36 monthly return observations are required for estimation. MkttoBook is the market value of equity divided by the book value of equity computed from Compustat as ((data199* data25)/data216). Tenure is the CEO's tenure with the firm in years, as provided by Equilar. OutsideChmn is a dichotomous variable that equals one if the board chairman is delineated as an outsider by Equilar and is zero otherwise. OutsideLdDir is a dichotomous variable that equals one if the lead independent director is delineated as an outsider by Equilar and is zero otherwise. CEOApptdOutsDirs is the number of outside directors whose tenure is less than the CEO's tenure, scaled by the total number of directors. StaggeredBd is a dichotomous variable that equals one if Equilar delineates the board service terms as staggered and is zero otherwise. PctOldOutsDirs is the ratio of outside directors who are at least 69 years old to total directors. PctBusyOutsDirs is the ratio of outside directors who serve simultaneously on at least two boards to total directors. PctFoundingDirs is the ratio of directors who are founding firm members to total directors.

OutsideDirHolds is the sum of shares held by outside directors to total shares outstanding. NumberDirs is the number of directors on the board. PctFinExpsAud is the ratio of directors with financial expertise who serve on the audit committee to total directors. Directors are classified as financial experts if they have experience as CEO, CFO, financial accountant, or auditor, or if they have been licensed as a Certified Public or Chartered Accountant. DirCompMix is the ratio of total dollar equity compensation to total equity plus cash compensation for non-executive directors. NumberInstOwns is the number of institutional owners delineated in the CDA/Spectrum database. NumBlockhldrs is the number of institutional owners that own at least $5 \%$ of outstanding shares. Activists is the number of institutional owners denoted as activists by Cremers and Nair (2005) and Larcker, Richardson, and Tuna (2007). 


\section{Table 6}

\section{Accounting Irregularities}

Frequency of observed accounting irregularities for the treatment (high CEO equity incentives) and the control (low CEO equity incentives) groups

Panel A. Accounting Manipulation-Related Restatements

\begin{tabular}{|c|c|c|c|c|c|c|c|c|c|c|c|c|c|}
\hline \multicolumn{2}{|c|}{ EqIncQuint $_{t}$} & \multicolumn{6}{|c|}{ Restatement Frequency $_{t}$} & \multicolumn{6}{|c|}{ Restatement Frequency $_{t+1}$} \\
\hline $\mathrm{T}$ & $\mathrm{C}$ & $\mathrm{T}$ & $\mathrm{C}$ & $p$ & $\Gamma$ & $\$$ Incent $_{\mathrm{T}}$ & SIncent $_{\mathrm{C}}$ & $\mathrm{T}$ & $\mathrm{C}$ & $p$ & $\Gamma$ & SIncent $_{\mathrm{T}}$ & SIncent $_{\mathrm{C}}$ \\
\hline 5 & 4 & 38 & 40 & 0.910 & & $1,582,081$ & 501,198 & 31 & 55 & 0.013 & 1.37 & $1,529,602$ & 528,784 \\
\hline 5 & 3 & 8 & 11 & 0.646 & & & & 15 & 16 & 1.000 & & & \\
\hline 5 & 2 & 4 & 4 & 0.724 & & & & 2 & 4 & 0.683 & & & \\
\hline 5 & 1 & 0 & 3 & 0.248 & & & & 2 & 1 & 1.000 & & & \\
\hline 4 & 3 & 29 & 38 & 0.328 & & 472,528 & 222,198 & 29 & 33 & 0.703 & & 450,777 & 223,529 \\
\hline 4 & 2 & 16 & 17 & 1.000 & & & & 11 & 11 & 0.831 & & & \\
\hline 4 & 1 & 0 & 0 & 1.000 & & & & 1 & 0 & 1.000 & & & \\
\hline 3 & 2 & 36 & 32 & 0.716 & & 204,615 & 96,106 & 35 & 44 & 0.368 & & 185,660 & 91,726 \\
\hline 3 & 1 & 7 & 8 & 1.000 & & & & 9 & 4 & 0.267 & & & \\
\hline 2 & 1 & 23 & 21 & 0.880 & & 83,670 & 29,833 & 24 & 21 & 0.766 & & 78,978 & 25,552 \\
\hline Pooled & Pooled & 161 & 174 & 0.512 & & 429,801 & 147,548 & 159 & 189 & 0.120 & & 713,271 & 178,435 \\
\hline \multicolumn{2}{|c|}{ DiffEqIncQuint $t_{t}$} & \multicolumn{6}{|c|}{ Restatement Frequency $_{t}$} & \multicolumn{6}{|c|}{ Restatement Frequency $_{t+1}$} \\
\hline \multicolumn{2}{|c|}{$\mathrm{T}-\mathrm{C}$} & $\mathrm{T}$ & $\mathrm{C}$ & $p$ & $\Gamma$ & SIncent $_{\mathrm{T}}$ & \$Incent $\mathrm{C}_{\mathrm{C}}$ & $\mathrm{T}$ & $\mathrm{C}$ & $p$ & $\Gamma$ & SIncent $_{\mathrm{T}}$ & SIncent $_{\mathrm{C}}$ \\
\hline \multicolumn{2}{|c|}{4} & 0 & 3 & 0.248 & & & & 2 & 1 & 1.000 & & & \\
\hline \multicolumn{2}{|c|}{3} & 4 & 4 & 0.724 & & & & 3 & 4 & 1.000 & & & \\
\hline \multicolumn{2}{|c|}{2} & 31 & 36 & 0.625 & & & & 35 & 31 & 0.712 & & & \\
\hline \multicolumn{2}{|c|}{1} & 126 & 131 & 0.803 & & 368,860 & 167,047 & 119 & 153 & 0.045 & 1.04 & 371,114 & 162,026 \\
\hline
\end{tabular}




\section{Table 6 (continued)}

\section{Accounting Irregularities}

Frequency of observed accounting irregularities for the treatment (high CEO equity incentives) and the control (low CEO equity incentives) groups

Panel B. Accounting-Related Shareholder Lawsuits

\begin{tabular}{|c|c|c|c|c|c|c|c|c|c|c|c|c|c|}
\hline \multicolumn{2}{|c|}{ EqIncQuint $_{t}$} & \multicolumn{6}{|c|}{ Lawsuit Frequency $_{t}$} & \multicolumn{6}{|c|}{ Lawsuit Frequency $_{t+1}$} \\
\hline $\mathrm{T}$ & $\mathrm{C}$ & $\mathrm{T}$ & $\mathrm{C}$ & $p$ & $\Gamma$ & SIncent $_{\mathrm{T}}$ & SIncent ${ }_{\mathrm{C}}$ & $\mathrm{T}$ & $\mathrm{C}$ & $P$ & $\Gamma$ & SIncent $_{\mathrm{T}}$ & \$Incent $\mathrm{C}_{\mathrm{C}}$ \\
\hline 5 & 4 & 42 & 65 & 0.033 & 1.13 & $1,596,888$ & 527,222 & 31 & 41 & 0.289 & & $1,474,446$ & 524,969 \\
\hline 5 & 3 & 6 & 16 & 0.055 & 1.49 & & & 7 & 22 & 0.009 & 3.15 & & \\
\hline 5 & 2 & 4 & 8 & 0.386 & & & & 5 & 5 & 0.752 & & & \\
\hline 5 & 1 & 4 & 5 & 1.000 & & & & 4 & 1 & 0.371 & & & \\
\hline 4 & 3 & 31 & 36 & 0.625 & & 451,960 & 226,679 & 22 & 17 & 0.522 & & 401,866 & 183,203 \\
\hline 4 & 2 & 17 & 17 & 0.864 & & & & 11 & 13 & 0.838 & & & \\
\hline 4 & 1 & 1 & 0 & 1.000 & & & & 0 & 0 & 1.000 & & & \\
\hline 3 & 2 & 31 & 24 & 0.418 & & 184,689 & 74,294 & 12 & 26 & 0.035 & 1.41 & 170,823 & 75,432 \\
\hline 3 & 1 & 0 & 2 & 0.480 & & & & 1 & 1 & 0.480 & & & \\
\hline 2 & 1 & 7 & 14 & 0.190 & & 77,684 & 24,576 & 5 & 7 & 0.773 & & 65,287 & 24,233 \\
\hline Pooled & Pooled & 143 & 187 & 0.018 & 1.06 & 630,373 & 189,108 & 98 & 133 & 0.025 & 1.07 & 713,271 & 178,435 \\
\hline \multicolumn{2}{|c|}{ DiffEqIncQuint $_{t}$} & \multicolumn{6}{|c|}{ Lawsuit Frequency $_{t}$} & \multicolumn{6}{|c|}{ Lawsuit Frequency $_{t+1}$} \\
\hline \multicolumn{2}{|c|}{$\mathrm{T}-\mathrm{C}$} & $\mathrm{T}$ & $\mathrm{C}$ & $p$ & $\Gamma$ & SIncent $_{\mathrm{T}}$ & SIncent $\mathrm{C}_{\mathrm{C}}$ & $\mathrm{T}$ & $\mathrm{C}$ & $P$ & $\Gamma$ & sIncent $_{\mathrm{T}}$ & SIncent ${ }_{\mathrm{C}}$ \\
\hline \multicolumn{2}{|c|}{4} & 4 & 5 & 1.000 & & & & 4 & 1 & 0.371 & & & \\
\hline \multicolumn{2}{|c|}{3} & 5 & 8 & 0.579 & & & & 5 & 5 & 0.752 & & & \\
\hline \multicolumn{2}{|c|}{2} & 23 & 35 & 0.149 & & & & 19 & 36 & 0.031 & 1.30 & & \\
\hline \multicolumn{2}{|c|}{1} & 111 & 139 & 0.088 & 1.01 & 568,488 & 276,337 & 70 & 91 & 0.115 & & 581,103 & 265,093 \\
\hline
\end{tabular}


Table 6 (continued)

\section{Accounting Irregularities}

Frequency of observed Accounting Irregularities for the treatment (high CEO equity incentives) and the control (low CEO equity incentives) groups

Panel C. Accounting-Related SEC Enforcement Actions (AAERs)

\begin{tabular}{|c|c|c|c|c|c|c|c|c|c|c|c|c|c|}
\hline \multicolumn{2}{|c|}{ EqIncQuint $_{t}$} & \multicolumn{6}{|c|}{ AAER Frequency $y_{t}$} & \multicolumn{6}{|c|}{ AAER Frequency ${ }_{t+1}$} \\
\hline $\mathrm{T}$ & $\mathrm{C}$ & $\mathrm{T}$ & $\mathrm{C}$ & $p$ & $\Gamma$ & SIncent $_{\mathrm{T}}$ & SIncent $_{\mathrm{C}}$ & $\mathrm{T}$ & $\mathrm{C}$ & $P$ & $\Gamma$ & SIncent $_{\mathrm{T}}$ & SIncent ${ }_{\mathrm{C}}$ \\
\hline 5 & 4 & 9 & 29 & 0.002 & 6.26 & $1,636,782$ & 477,647 & 7 & 19 & 0.031 & 1.80 & $1,523,063$ & 514,917 \\
\hline 5 & 3 & 2 & 5 & 0.450 & & & & 3 & 0 & 0.248 & & & \\
\hline 5 & 2 & 0 & 2 & 0.480 & & & & 0 & 1 & 1.000 & & & \\
\hline 5 & 1 & 2 & 1 & 1.000 & & & & 2 & 0 & 0.480 & & & \\
\hline 4 & 3 & 10 & 10 & 0.823 & & 439,622 & 243,417 & 9 & 5 & 0.423 & & 381,774 & 238,192 \\
\hline 4 & 2 & 4 & 11 & 0.121 & & & & 3 & 6 & 0.505 & & & \\
\hline 4 & 1 & 0 & 0 & 0.000 & & & & 1 & 0 & 1.000 & & & \\
\hline 3 & 2 & 10 & 11 & 1.000 & & 183,834 & 81,296 & 6 & 12 & 0.239 & & 177,221 & 72,115 \\
\hline 3 & 1 & 1 & 1 & 0.480 & & & & 1 & 0 & 1.000 & & & \\
\hline 2 & 1 & 6 & 3 & 0.505 & & 72,381 & 23,258 & 4 & 3 & 1.000 & & 60,539 & 19,342 \\
\hline Pooled & Pooled & 44 & 73 & 0.010 & 1.32 & 557,843 & 153,427 & 36 & 46 & 0.320 & & 406,358 & 120,498 \\
\hline \multicolumn{2}{|c|}{ DiffEqIncQuint $_{t}$} & \multicolumn{6}{|c|}{ AAER Frequency $y_{t}$} & \multicolumn{6}{|c|}{ AAER Frequency $_{t+1}$} \\
\hline \multicolumn{2}{|c|}{$\mathrm{T}-\mathrm{C}$} & $\mathrm{T}$ & $\mathrm{C}$ & $p$ & $\Gamma$ & SIncent $_{\mathrm{T}}$ & SIncent $_{\mathrm{C}}$ & $\mathrm{T}$ & $\mathrm{C}$ & $P$ & $\Gamma$ & SIncent $_{\mathrm{T}}$ & SIncent $_{\mathrm{C}}$ \\
\hline \multicolumn{2}{|c|}{4} & 2 & 1 & 1.000 & & & & 2 & 0 & 0.480 & & & \\
\hline \multicolumn{2}{|c|}{3} & 0 & 2 & 0.480 & & & & 1 & 1 & 0.480 & & & \\
\hline \multicolumn{2}{|c|}{2} & 7 & 17 & 0.066 & 1.29 & & & 7 & 6 & 1.000 & & & \\
\hline \multicolumn{2}{|c|}{1} & 35 & 53 & 0.070 & 1.05 & 504,338 & 249,946 & 26 & 39 & 0.137 & & 372,203 & 212,802 \\
\hline
\end{tabular}

EqIncQuint is a dichotomous variable that equals one if the CEO's portfolio delta falls within the $k$ th quintile of the cross-sectional distribution of CEO deltas and equals zero otherwise. The portfolio delta is the change in dollar value of the CEO's equity portfolio for a $1 \%$ change in the firm's underlying stock price. DiffEqIncQuint is the difference between EqIncQuint for the Treatment and Control groups. Each cell contains the discordant pair frequency of observing an accounting irregularity. In other words, the frequency count in the Treatment category denotes the number of observations for which there is an observed accounting irregularity in the treatment group but no observed accounting irregularity in the control group. $p$-values are computed using a McNemar's non-parametric test for differences in frequency across distributions. $\Gamma$ values quantify the amount of hidden bias necessary to alter the statistical significance $(p=0.10)$ that results from the assumption that two observations with identical propensity scores have an equal probability of receiving treatment. \$Incent is the median portfolio delta computed for the Treatment and Control matched observations reported in the frequency cells. \$Incent is reported only when DiffEqIncQuint $=1$ (and for Pooled data), since this reflects the minimum equity-incentive distance and there is sufficient sample size for tests of median differences. All $\$$ Incent $t_{\mathrm{T}}-\$$ Incent $_{\mathrm{C}}$ differences are statistically significant at the $1 \%$ level (two-tailed) using a Kruskal-Wallis test. 


\section{Table 7}

\section{Sensitivity Analysis: Conditional Logistic Regression}

\section{Panel A. Regression Estimates}

\begin{tabular}{|c|c|c|c|c|c|c|}
\hline & \multicolumn{2}{|c|}{ Restatement $t_{t}$} & \multicolumn{2}{|c|}{ Lawsuit } & \multicolumn{2}{|c|}{$\overline{A A E R_{t}}$} \\
\hline & Coeff. & $\mathrm{z}$-Stat & Coeff. & z-Stat & Coeff. & z-Stat \\
\hline EqIncQuint $_{2}=1$ & 0.037 & 0.10 & -0.219 & -0.60 & -0.794 & -0.72 \\
\hline EqIncQuint $_{3}=1$ & -0.014 & -0.06 & -0.193 & -0.67 & -0.412 & -0.36 \\
\hline EqIncQuint $_{4}=1$ & -0.288 & -0.66 & -0.012 & -0.03 & -0.174 & -0.17 \\
\hline EqIncQuint $_{5}=1$ & -0.406 & -0.94 & -0.613 & -1.35 & -1.382 & -1.09 \\
\hline Matched CEO-firm-year obs. & & 770 & & 798 & & 262 \\
\hline Adj. Pseudo- $R^{2}$ & & 0.144 & & 0.198 & & 0.429 \\
\hline Tests of Coefficients & & p-Value & & p-Value & & p-Value \\
\hline EqIncQuint $_{2}=1 \neq$ EqIncQuint $_{3}=1$ & & 0.89 & & 0.90 & & 0.38 \\
\hline EqIncQuint $_{2}=1 \neq$ EqIncQuint $_{4}=1$ & & 0.38 & & 0.51 & & 0.32 \\
\hline EqIncQuint $_{2}=1 \neq$ EqIncQuint $_{5}=1$ & & 0.20 & & 0.23 & & 0.52 \\
\hline EqIncQuint $_{3}=1 \neq$ EqIncQuint $_{4}=1$ & & 0.47 & & 0.40 & & 0.75 \\
\hline EqIncQuint $_{3}=1 \neq$ EqIncQuint $_{5}=1$ & & 0.24 & & 0.12 & & 0.31 \\
\hline \multirow[t]{3}{*}{ EqIncQuint $_{4}=1 \neq$ EqIncQuint $_{5}=1$} & & 0.74 & & 0.02 & & 0.13 \\
\hline & \multicolumn{2}{|c|}{ Restatement $t_{t+1}$} & \multicolumn{2}{|c|}{ Lawsuit $_{t+1}$} & \multicolumn{2}{|c|}{$\overline{A A E R_{t+1}}$} \\
\hline & Coeff. & z-Stat & Coeff. & z-Stat & Coeff. & z-Stat \\
\hline EqIncQuint $_{2}=1$ & -0.372 & -1.41 & -0.076 & -0.17 & 1.666 & 1.19 \\
\hline EqIncQuint $_{3}=1$ & -0.073 & -0.24 & -0.163 & -0.33 & -0.691 & -0.39 \\
\hline EqIncQuint $_{4}=1$ & -0.108 & -0.33 & -0.115 & -0.20 & 2.258 & 1.13 \\
\hline EqIncQuint $_{5}=1$ & -0.767 & -1.79 & -0.263 & -0.58 & 0.437 & 0.24 \\
\hline Matched CEO-firm-year obs. & & 668 & & 514 & & 176 \\
\hline Adj. Pseudo- $R^{2}$ & & 0.095 & & 0.184 & & 0.506 \\
\hline Tests of Coefficients & & p-Value & & p-Value & & p-Value \\
\hline EqIncQuint $_{2}=1 \neq$ EqIncQuint $_{3}=1$ & & 0.89 & & 0.81 & & 0.01 \\
\hline EqIncQuint $_{2}=1 \neq$ EqIncQuint $_{4}=1$ & & 0.38 & & 0.93 & & 0.60 \\
\hline EqIncQuint $_{2}=1 \neq$ EqIncQuint $_{5}=1$ & & 0.20 & & 0.69 & & 0.40 \\
\hline EqIncQuint $_{3}=1 \neq$ EqIncQuint $_{4}=1$ & & 0.47 & & 0.90 & & 0.00 \\
\hline EqIncQuint $_{3}=1 \neq$ EqIncQuint $_{5}=1$ & & 0.24 & & 0.76 & & 0.19 \\
\hline EqIncQuint $_{4}=1 \neq$ EqIncQuint $_{5}=1$ & & 0.74 & & 0.71 & & 0.12 \\
\hline
\end{tabular}


Table 7

Sensitivity Analysis: Conditional Logistic Regression (continued)

Panel B. Covariate Balance Between Irregularity and Matched Observations

\begin{tabular}{|c|c|c|c|c|c|c|c|}
\hline & $\begin{array}{c}\text { Table } 5 \\
\text { Median } \\
\text { Trt.-Cnntrl. } \\
\end{array}$ & $\begin{array}{l}\text { Restatement } \\
\text { Median } \\
\text { Irreg.-Match }\end{array}$ & $\begin{array}{l}\text { Restatement } t_{t+1} \\
\text { Median } \\
\text { Irreg.-Match }\end{array}$ & $\begin{array}{c}\text { Lawsuit }_{t} \\
\text { Median } \\
\text { Irreg.-Match } \\
\end{array}$ & $\begin{array}{c}\begin{array}{c}\text { Lawsuit } \\
\text { Median }\end{array} \\
\text { Irreg.-Match } \\
\end{array}$ & $\begin{array}{c}A A E R_{t} \\
\text { Median } \\
\text { Irreg.-Match } \\
\end{array}$ & $\begin{array}{c}A A E R_{t+1} \\
\text { Median } \\
\text { Irreg.-Match } \\
\end{array}$ \\
\hline PortDelta & $1.193^{* * *}$ & $-0.291^{* * *}$ & -0.117 & -0.209 & 0.029 & $-0.248^{*}$ & 0.050 \\
\hline Leverage & 0.000 & $0.034^{* * *}$ & $0.019^{* * *}$ & $0.010^{* * *}$ & 0.000 & $0.027^{* * *}$ & $0.019^{* * *}$ \\
\hline Log(MarketCap) & 0.041 & 0.000 & 0.002 & 0.003 & 0.002 & 0.002 & 0.002 \\
\hline Log(Idiosyncrisk) & $-0.036^{* * *}$ & $0.059^{* * *}$ & 0.041 & $0.118^{* * *}$ & $0.116^{* * *}$ & $0.134^{* *}$ & $0.127^{* *}$ \\
\hline MkttoBook & $0.057^{* * *}$ & $-0.312^{* * *}$ & $-0.277^{* *}$ & -0.105 & -0.026 & $-0.320^{* *}$ & -0.082 \\
\hline $\log (1+$ Tenure $)$ & $0.000^{* * *}$ & $-0.261^{* * *}$ & 0.000 & 0.000 & $0.169^{*}$ & $-0.000^{*}$ & 0.084 \\
\hline OutsideChmn & 0.000 & 0.000 & 0.000 & 0.000 & 0.000 & 0.000 & 0.000 \\
\hline OutsideLdDir & 0.000 & 0.000 & 0.000 & 0.000 & 0.000 & 0.000 & 0.000 \\
\hline CEOApptdOutsDirs & 0.000 & $-0.066^{* *}$ & 0.000 & 0.000 & 0.000 & 0.000 & 0.000 \\
\hline StaggeredBd & 0.000 & 0.000 & 0.000 & 0.000 & 0.000 & 0.000 & 0.000 \\
\hline PctOldOutsDirs & 0.000 & 0.000 & 0.000 & $0.000^{* * *}$ & 0.000 & $-0.000^{*}$ & 0.000 \\
\hline PctBusyOutsDirs & 0.000 & 0.000 & 0.015 & 0.000 & 0.000 & -0.033 & -0.054 \\
\hline PctFoundingDirs & 0.000 & 0.000 & 0.000 & 0.000 & 0.000 & 0.000 & 0.000 \\
\hline OutsideDirHolds & 0.000 & 0.000 & 0.000 & 0.000 & 0.000 & 0.000 & 0.000 \\
\hline Log(NumberDirs) & 0.000 & 0.068 & 0.000 & 0.000 & 0.000 & 0.000 & 0.000 \\
\hline PctFinExpsAud & 0.000 & 0.000 & 0.000 & 0.000 & 0.000 & 0.000 & 0.000 \\
\hline DirCompMix & 0.000 & -0.004 & 0.000 & $0.035^{* *}$ & $0.077^{* * *}$ & -0.050 & -0.025 \\
\hline Log(NumInstOwns) & 0.000 & 0.063 & 0.057 & $0.079^{* *}$ & $0.083^{* * *}$ & 0.141 & 0.115 \\
\hline Log(NumBlockhldrs) & 0.000 & 0.000 & 0.000 & 0.000 & 0.000 & 0.000 & 0.000 \\
\hline $\log$ (Activists) & 0.000 & 0.000 & 0.000 & 0.000 & 0.000 & 0.000 & 0.000 \\
\hline Number of pairs & 4,559 & 385 & 334 & 399 & 257 & 131 & 88 \\
\hline
\end{tabular}

EqIncQuint is a dichotomous variable that equals one if the CEO's portfolio delta (PortDelta) falls within the $k$ th quintile of the cross-sectional distribution of CEO deltas and equals zero otherwise. PortDelta is the change in dollar value of the CEO's equity portfolio for a $1 \%$ change in the firm's underlying stock price. Leverage is the ratio of total debt to market value of assets computed from Compustat as (data $9+$ data34)/(data199* data25) + data9). MarketCap is the market value of equity computed from Compustat as (data199* data25). Idiosyncrisk is the standard deviation of residuals from a firm-specific regression of monthly returns on the monthly return to the CRSP value-weighted portfolio index (Core and Guay, 1999). At least 12 and no more than 36 monthly return observations are required for estimation. MkttoBook is the market value of equity divided by the book value of equity computed from Compustat as ((data199* data25)/data216). Tenure is the CEO's tenure with the firm in years, as provided by Equilar. OutsideChmn is a dichotomous variable that equals one if the board chairman is delineated as an outsider by Equilar and is zero otherwise. OutsideLdDir is a dichotomous variable that equals one if the lead independent director is delineated as an outsider by Equilar and is zero otherwise. CEOApptdOutsDirs is the number of outside directors whose tenure is less than the CEO's tenure, scaled by the total number of directors. StaggeredBd is a dichotomous 
variable that equals one if Equilar delineates the board service terms as staggered and is zero otherwise. PctOldOutsDirs is the ratio of outside directors who are at least 69 years old to total directors. PctBusyOutsDirs is the ratio of outside directors who serve simultaneously on at least two boards to total directors. PctFoundingDirs is the ratio of directors who are founding firm members to total directors. OutsideDirHolds is the sum of shares held by outside directors to total shares outstanding.

NumberDirs is the number of directors on the board. PctFinExpsAud is the ratio of directors with financial expertise who serve on the audit committee to total directors. DirCompMix is the ratio of total dollar equity compensation to total equity plus cash compensation for non-executive directors. NumberInstOwns is the number of institutional owners delineated in the CDA/Spectrum database. NumBlockhldrs is the number of institutional owners that own at least $5 \%$ of outstanding shares. Activists is the number of institutional owners denoted as activists by Cremers and Nair (2005) and Larcker, Richardson, and Tuna (2007). *,**, and *** denote statistical significance at the $0.10,0.05$, and 0.01 levels, respectively, from a KS bootstrap test of median differences. 
Table 8

Sensitivity Analysis: Early Sample

Panel A. Regression estimates

\begin{tabular}{|c|c|c|c|c|}
\hline & \multicolumn{2}{|c|}{$\overline{A A E R_{t}}$} & \multicolumn{2}{|c|}{$\overline{A A E R_{t}}$} \\
\hline & Coeff. & $\mathrm{z}$-Stat & Coeff. & z-Stat \\
\hline EqIncQuint $_{2}=1$ & -0.155 & -0.21 & -0.040 & -0.04 \\
\hline EqIncQuint $_{3}=1$ & 0.642 & 0.87 & 1.066 & 1.00 \\
\hline EqIncQuint $_{4}=1$ & 0.099 & 0.13 & 1.158 & 0.97 \\
\hline EqIncQuint $_{5}=1$ & 1.063 & 1.36 & 3.414 & 2.30 \\
\hline$C E O$ - firm-year obs. & & 150 & & 150 \\
\hline Adj. Pseudo- $R^{2}$ & & 0.191 & & 0.412 \\
\hline Estimation Method & & Logistic & & Cond. Logistic \\
\hline Tests of Coefficients & & p-Value & & p-Value \\
\hline EqIncQuint $_{2}=1 \neq$ EqIncQuint $_{3}=1$ & & 0.25 & & 0.25 \\
\hline EqIncQuint $_{2}=1 \neq$ EqIncQuint $_{4}=1$ & & 0.72 & & 0.23 \\
\hline EqIncQuint $_{2}=1 \neq$ EqIncQuint $_{5}=1$ & & 0.09 & & 0.01 \\
\hline EqIncQuint $_{3}=1 \neq$ EqIncQuint $_{4}=1$ & & 0.39 & & 0.91 \\
\hline EqIncQuint $_{3}=1 \neq$ EqIncQuint $_{5}=1$ & & 0.50 & & 0.02 \\
\hline EqIncQuint $_{4}=1 \neq$ EqIncQuint $_{5}=1$ & & 0.12 & & 0.02 \\
\hline
\end{tabular}




\section{Table 8}

\section{Sensitivity Analysis: Early Sample (continued)}

\section{Panel B. AAER frequency for treatment (high CEO equity incentives) and control}

(low CEO equity incentives) groups, matched by propensity score

\begin{tabular}{|c|c|c|c|c|c|}
\hline \multicolumn{2}{|c|}{ EqIncQuint } & \multicolumn{4}{|c|}{ AAER Frequency } \\
\hline $\bar{T}$ & $\mathrm{C}$ & $\mathbf{T}$ & C & $p$ & $\Gamma$ \\
\hline 5 & 4 & 16 & 5 & 0.029 & 1.68 \\
\hline 5 & 3 & 0 & 0 & 1.000 & \\
\hline 5 & 2 & 0 & 0 & 1.000 & \\
\hline 5 & 1 & 0 & 0 & 1.000 & \\
\hline 4 & 3 & 3 & 6 & 0.505 & \\
\hline 4 & 2 & 0 & 0 & 1.000 & \\
\hline 4 & 1 & 0 & 0 & 1.000 & \\
\hline 3 & 2 & 3 & 2 & 1.000 & \\
\hline 3 & 1 & 0 & 0 & 1.000 & \\
\hline 2 & 1 & 2 & 13 & 0.010 & 11.92 \\
\hline Pooled & Pooled & 24 & 26 & 0.888 & \\
\hline
\end{tabular}

\begin{tabular}{crrrrr} 
DiffEqIncQuint & & \multicolumn{4}{c}{ AAER Frequency } \\
\cline { 1 - 4 } \cline { 4 - 6 } T - C & & T & C & $\boldsymbol{p}$ & $\boldsymbol{\Gamma}$ \\
\hline 4 & & 0 & 0 & 1.000 & \\
3 & 0 & 0 & 1.000 & \\
2 & 0 & 0 & 1.000 & \\
1 & 24 & 26 & 0.888 & \\
\hline
\end{tabular}

Regression statistics in Panel A derive from logistic or conditional logistic regression of $A A E R=\beta_{1}+\sum_{k=2}^{5} \beta_{k}$

EqIncQuint $_{k}+\beta_{6} C E O=C H A I R+\beta_{7}$ NUMMTGS $+\beta_{8}$ FINANCING $+\beta_{9}$ LEVERAGE $+\beta_{10}$ MARKET VALUE OF EQUITY $+\beta_{11}$ ALTMAN'S Z $+\beta_{12}$ BOOK TO MARKET $+\beta_{13}$ EARNINGS TO PRICE $+\beta_{14}$ RET ON ASSETS $+\beta_{15}$ SALES GROWTH $+\beta_{16}$ AGE OF FIRM $+\beta_{17}$ M\&A IN FIRST YEAR OF FRAUD $+\beta_{18}$ STOCK VOLATILITY $+\beta_{19}$ CEO TENURE $+\beta_{20}$ MISSING CEO TENURE $+\varepsilon_{i}$.

EqIncQuint is a dichotomous variable that equals one if the CEO's portfolio delta falls within the $k$ th quintile of the cross-sectional distribution of CEO deltas and equals zero otherwise. The portfolio delta is the change in dollar value of the CEO's equity portfolio for a 1\% change in the firm's underlying stock price. See Erickson, Hanlon, and Maydew (2006) for other variable definitions.

Cells in Panel B contain the discordant pair frequency of observing an accounting irregularity. In other words, the frequency count in the Treatment category denotes the number of observations where there is an observed accounting irregularity in the treatment group but no observed accounting irregularity in the control group. $p$-values are computed using a McNemar's non-parametric test for differences in frequency across distributions. DiffEqIncQuint is the difference between EqIncQuint for the Treatment and Control groups. Propensity scores are estimated through logistic regression of EqIncQuint $=\beta_{1}+\beta_{2} C E O=C H A I R+\beta_{3} N U M M T G S+\beta_{4}$ FINANCING $+\beta_{5}$ LEVERAGE $+\beta_{6}$ MARKET VALUE OF EQUITY $+\beta_{7}$ ALTMAN'S $Z+\beta_{8}$ BOOK TO MARKET $+\beta_{9}$ EARNINGS TO PRICE $+\beta_{10}$ RET ON ASSETS $+\beta_{11}$ SALES GROWTH $+\beta_{12}$ AGE OF FIRM $+\beta_{13}$ M\&A IN FIRST YEAR OF FRAUD $+\beta_{14}$ STOCK VOLATILITY $+\beta_{15}$ CEO TENURE $+\beta_{16}$ MISSING CEO TENURE $+\varepsilon_{i}$. 
$\Gamma$ values quantify the amount of hidden bias necessary to alter the statistical significance $(p=0.10)$ that results from the assumption that two observations with identical propensity scores have an equal probability of receiving treatment. 